\title{
Parameterization retrieval of trace gas volume mixing ratios from Airborne MAX-DOAS
}

\author{
Barbara Dix $^{1}$, Theodore K. Koenig ${ }^{1,2}$, and Rainer Volkamer ${ }^{1,2}$ \\ ${ }^{1}$ Department of Chemistry and Biochemistry, University of Colorado, Boulder, CO, USA \\ ${ }^{2}$ CIRES, University of Colorado, Boulder, CO, USA \\ Correspondence to: Rainer Volkamer (rainer.volkamer@colorado.edu)
}

Received: 15 May 2016 - Published in Atmos. Meas. Tech. Discuss.: 11 July 2016

Revised: 24 October 2016 - Accepted: 8 November 2016 - Published: 28 November 2016

\begin{abstract}
We present a parameterization retrieval of volume mixing ratios (VMRs) from differential slant column density (dSCD) measurements by Airborne Multi-AXis Differential Optical Absorption Spectroscopy (AMAX-DOAS). The method makes use of the fact that horizontally recorded limb spectra (elevation angle $0^{\circ}$ ) are strongly sensitive to the atmospheric layer at instrument altitude. These limb spectra are analyzed using reference spectra that largely cancel out column contributions from above and below the instrument, so that the resulting limb dSCDs, i.e., the column integrated concentration with respect to a reference spectrum, are almost exclusively sensitive to the atmospheric layers around instrument altitude. The conversion of limb dSCDs into VMRs is then realized by calculating box air mass factors (Box-AMFs) for a Rayleigh atmosphere and applying a scaling factor constrained by $\mathrm{O}_{4}$ dSCDs to account for aerosol extinction. An iterative VMR retrieval scheme corrects for trace gas profile shape effects. Benefits of this method are (1) a fast conversion that only requires the computation of Box-AMFs in a Rayleigh atmosphere; (2) neither local aerosol extinction nor the slant column density in the DOAS reference ( $\mathrm{SCD}_{\text {ref }}$ ) needs to be known; and (3) VMRs can be retrieved for every measurement point along a flight track, thus increasing statistics and adding flexibility to capture concentration gradients.

Sensitivity studies are performed for bromine monoxide $(\mathrm{BrO})$, iodine monoxide (IO) and nitrogen dioxide $\left(\mathrm{NO}_{2}\right)$, using (1) simulated dSCD data for different trace gas and aerosol profiles and (2) field measurements from the Tropical Ocean tRoposphere Exchange of Reactive halogen species and Oxygenated VOC (TORERO) field experiment. For simulated data in a Rayleigh atmosphere,
\end{abstract}

the agreement between the VMR from the parameterization method $\left(\mathrm{VMR}_{\text {para }}\right)$ and the true $\mathrm{VMR}\left(\mathrm{VMR}_{\text {true }}\right)$ is excellent for all trace gases. Offsets, slopes and $R^{2}$ values for the linear fit of $\mathrm{VMR}_{\text {para }}$ over $\mathrm{VMR}_{\text {true }}$ are, respectively $(0.008 \pm 0.001)$ pptv, $0.988 \pm 0.001,0.987$ for $\mathrm{BrO} ;(-0.0066 \pm 0.0001)$ pptv, $1.0021 \pm 0.0003,0.9979$ for IO; $(-0.17 \pm 0.03)$ pptv, $1.0036 \pm 0.0001,0.9997$ for $\mathrm{NO}_{2}$. The agreement for atmospheres with aerosol shows comparable $R^{2}$ values to the Rayleigh case, but slopes deviate a bit more from one: $(0.093 \pm 0.002)$ pptv, $0.933 \pm 0.002$, 0.907 for $\mathrm{BrO} ; \quad(0.0021 \pm 0.0004) \mathrm{pptv}, \quad 0.887 \pm 0.001$, 0.973 for IO; $(8.5 \pm 0.1)$ pptv, $0.8302 \pm 0.0006,0.9923$ for $\mathrm{NO}_{2}$. VMR para from field data are further compared with optimal estimation retrievals $\left(\mathrm{VMR}_{\mathrm{OE}}\right)$. Least orthogonal distance fit of the data give the following equations: $\mathrm{BrO}_{\text {para }}=(0.1 \pm 0.2) \mathrm{pptv}+(0.95 \pm 0.14) \times \mathrm{BrO}_{\mathrm{OE}}$; $\mathrm{IO}_{\text {para }}=(0.01 \pm 0.02) \mathrm{pptv}+(1.00 \pm 0.12) \times \mathrm{IO}_{\mathrm{OE}}$; $\mathrm{NO}_{2 \text { para }}=(3.9 \pm 2.5) \mathrm{pptv}+(0.87 \pm 0.15) \times \mathrm{NO}_{2 \mathrm{OE}}$. Overall, we conclude that the parameterization retrieval is accurate with an uncertainty of $20 \%$ for IO, $30 \%$ for $\mathrm{BrO}$ and $\mathrm{NO}_{2}$, but not better than 0.05 pptv IO, 0.5 pptv $\mathrm{BrO}$ and 10 pptv $\mathrm{NO}_{2}$. The retrieval is applicable over a wide range of atmospheric conditions and measurement geometries and not limited to the interpretation of vertical profile measurements in the remote troposphere.

\section{Introduction}

Airborne Multi-AXis Differential Optical Absorption Spectroscopy (AMAX-DOAS) measurements are well suited to probe the vertical distribution of trace gases such as bromine 
monoxide $(\mathrm{BrO})$, iodine monoxide $(\mathrm{IO})$, nitrogen dioxide $\left(\mathrm{NO}_{2}\right)$, glyoxal $(\mathrm{CHOCHO})$, formaldehyde $(\mathrm{HCHO})$, nitrous acid (HONO) or the oxygen collision complex $\mathrm{O}_{4}$ (Melamed et al., 2003; Wang et al., 2005, 2006; Heue et al., 2005, 2011, 2014; Bruns et al., 2006; Dix et al., 2009, 2013; Merlaud et al., 2011; Prados-Roman et al., 2011; Baidar et al., 2013a, b; Oetjen et al., 2013; Baidar et al., 2015; Volkamer et al., 2015; Werner et al., 2016). AMAX-DOAS collects scattered sunlight along multiple lines of sight by changing the viewing direction of the light-collecting telescope to different elevation angles (EAs), here defined as the angle between horizon and line of sight. The selective combination of instrument and solar geometries maximizes sensitivity to different altitude layers in the atmosphere by enhancing the light paths through these layers. Generally MAX-DOAS measurements are most sensitive to absorbers at instrument altitude when using low EAs, while the sensitivity to stratospheric trace gases depends mostly on solar zenith angle (Hönninger et al., 2004). Trace gas differential slant column densities (dSCDs) are the primary product (level 1 data) when analyzing scattered light spectra with the DOAS technique (Platt and Stutz, 2008). DSCDs quantify the integrated concentration along all light paths contributing to the measured spectrum with respect to a reference spectrum, i.e., $d S C D=S C D-S C D_{\text {ref }}$, where $\mathrm{SCD}_{\text {ref }}$ is the slant column contained in the reference spectrum. In order to convert light-path-dependent dSCDs into a light-path-independent quantity, i.e., a vertical column density (VCD, the integrated concentration along a vertical column through the atmosphere) or a vertical concentration profile, the light paths contributing to each dSCD measurement need to be known. Photon paths can be simulated by radiative transfer models (RTMs). Since aerosol and clouds can strongly affect light path distributions, a typical method to retrieve VCDs or profile data from MAX-DOAS measurements is a two-step process. First, the aerosol extinction profile is retrieved, e.g., by utilizing information contained in measurements of $\mathrm{O}_{4}$ (Wagner et al., 2004), which has an atmospheric profile that is well described by local temperature and pressure (Thalman and Volkamer, 2013). Second, trace gas concentrations are retrieved through an inversion technique that applies RTM computed weighting functions for an atmosphere, including the prior retrieved aerosol extinction. This approach is well suited for individual case studies, but it is typically time consuming, computationally intensive and requires vertically resolved SCD measurements as input. The widespread application of MAX-DOAS measurements from ground, ship, aircraft, balloon or satellite platforms and the accumulation of large data sets has led to recent developments that parameterize radiative transfer to interpret $\mathrm{dSCD}$ measurements (Sinreich et al., 2010, 2013; Irie et al., 2011; Schreier et al., 2016). Building on Sinreich et al. (2013), we present a parameterization retrieval of volume mixing ratios (VMRs) from AMAX-DOAS trace gas dSCDs. This study is organized as follows: Sect. 2 introduces the general principle of the retrieval, Sect. 3 describes a series of sensitivity studies using simulated data, while Sect. 4 discusses errors, strengths and limitations of the method. The parameterization retrieval is then applied to Tropical Ocean tRoposphere Exchange of Reactive halogen species and Oxygenated VOC (TORERO) field data in Sect. 5. Agreement with select optimal estimation $(\mathrm{OE})$ results is evaluated and TORERO IO and $\mathrm{BrO}$ results are discussed. Section 6 summarizes results and concludes on strengths and limitations of the retrieval.

\section{Parameterization retrieval}

\subsection{General principle}

The parameterization approach exploits the fact that spectra measured with EA $0^{\circ}$ are highly sensitive to instrument altitude. An EA $0^{\circ}$ spectrum is analyzed relative to a suitable reference spectrum, e.g., a zenith reference. As a result, trace gas contributions from atmospheric layers above and below the instrument are mostly canceled out and the respective $\mathrm{dSCD}$ is representative of a range of altitudes near the instrument altitude. The sensitivity of such an EA $0^{\circ} \mathrm{dSCD}$ measurement is quantified by box air mass factors (Box-AMFs) that are calculated for a Rayleigh atmosphere. Box-AMFs describe the sensitivity of a measurement to the partial VCD of an atmospheric layer. For optically thin absorbers, such as discussed here, the calculation of Box-AMFs is independent of the trace gas profile. Figure 1 shows dBox-AMFs (dBox$\left.\mathrm{AMF}=\mathrm{Box}-\mathrm{AMF}-\mathrm{Box}-\mathrm{AMF}_{\mathrm{ref}}\right)$ simulated at $477 \mathrm{~nm}$ for an instrument altitude of $5.25 \mathrm{~km}$ and a zenith reference from $7.75 \mathrm{~km}$. The Box-AMFs are calculated on a vertical grid with a total number of $N$ layers, where each layer $n$ has a constant grid height (dh) of $0.5 \mathrm{~km}$ up to $19 \mathrm{~km}$ and $1-2.5 \mathrm{~km}$ grid boxes above. The strong enhancement of dBox-AMFs at instrument altitude indicates the greatly enhanced sensitivity of AMAX-DOAS at instrument altitude. The altitude range with the largest dBox-AMFs is called the sensitive range, $S$ (grey shading in Fig. 1). It is demarcated by lower and upper boundary layers, $n_{\mathrm{L}}$ and $n_{\mathrm{U}}$. Initial sensitivity studies have shown that the parameterization method typically works best when about $90 \%$ of the sum over the dBox-AMF trace is included in $S$. Therefore the lower boundary $n_{\mathrm{L}}$ is set to $1 \mathrm{~km}$ below the instrument layer, $n_{\text {instr }}$, while $n_{\mathrm{U}}$ is set to the altitude layer before the difference between two consecutive dBox-AMFs is smaller than $10 \%$, and no more than $3.5 \mathrm{~km}$ above $n_{\text {instr }}$. Due to the distinct shape of the dBoxAMF (Fig. 1), the placement of the lower boundary is less critical and remains fixed, while the placement of the upper limit is more flexible. The dependency of $S$ on altitude, reference and wavelength is shown in Fig. S1 in the Supplement.

The basis of the parameterization retrieval is to treat each EA $0^{\circ} \mathrm{dSCD}$ as a measurement of $S$, i.e., $\mathrm{dSCD} \approx \mathrm{dSCD}(S)$, and then retrieve the trace gas concentration for the layer $n$ at instrument altitude, $n_{\text {instr }}$ (red shading in Fig. 1). To account for the effect of aerosol extinction on Box-AMFs in $S$, 


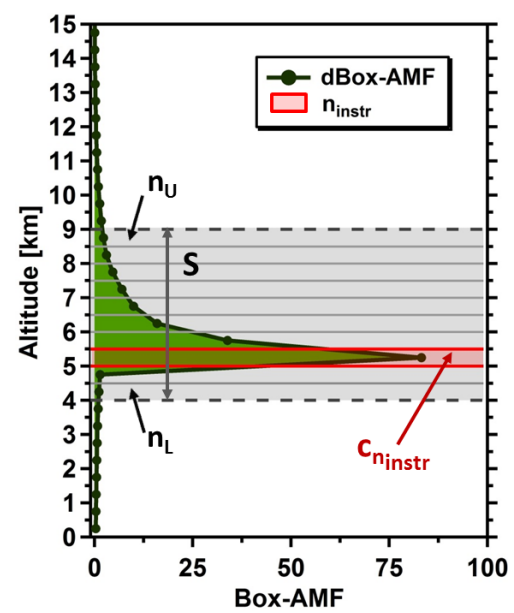

Figure 1. dBox-AMF values modeled at $477 \mathrm{~nm}$ on a $0.5 \mathrm{~km}$ grid (grey lines within $S$ ) for an EA $0^{\circ} \mathrm{dSCD}$ measurement at $5.25 \mathrm{~km}$ and a zenith reference from $7.75 \mathrm{~km}$, with a solar zenith angle of $10^{\circ}$. Grey shading indicates the sensitive range $S$ demarcated by the lower and upper limit layers $n_{\mathrm{L}}$ and $n_{\mathrm{U}}$. Green shading emphasizes the strong sensitivity of the EA $0^{\circ}$ measurement at instrument altitude, while the red box marks the instrument layer $n_{\text {instr }}$ for which the trace gas concentration $c_{n_{\text {instr }}}$ is being retrieved.

the simultaneously measured $\mathrm{O}_{4} \mathrm{dSCD}$ is used as scaling factor. The concentration at instrument altitude, $c_{n_{\text {instr }}}$, is derived iteratively in molecules per cubic centimeter $\left(\operatorname{molec} \mathrm{cm}^{-3}\right)$, with $i$ iterations, using the following equation:

$c_{n_{\text {instr }}}^{i}=\left(\mathrm{dSCD}+\mathrm{dSCD}_{\mathrm{c}}^{i}\right) \cdot \frac{c\left(\mathrm{O}_{4}\right)_{n_{\text {instr }}}}{\mathrm{O}_{4} \mathrm{dSCD}} \cdot f_{\mathrm{c}}^{i}$,

where dSCD is the trace gas dSCD measured at instrument altitude in molec $\mathrm{cm}^{-2}, \mathrm{dSCD}_{\mathrm{c}}^{i}$ is a correction term to account for remaining trace gas contributions from outside $S$ (see Sect. 2.2 below), $\mathrm{c}\left(\mathrm{O}_{4}\right)_{n_{\text {instr }}}$ is the $\mathrm{O}_{4}$ concentration in $n_{\text {instr }}$ in molec $^{2} \mathrm{~cm}^{-6}$ and $\mathrm{O}_{4} \mathrm{dSCD}$ is the simultaneously measured $\mathrm{O}_{4}$ slant column in molec $^{2} \mathrm{~cm}^{-5}$. Since the equilibrium constant for $\mathrm{O}_{4}$ is not well known, the $\mathrm{O}_{4}$ concentration is scaled to the square of the oxygen concentration. Based on temperature and pressure profiles, the $\mathrm{O}_{4}$ distribution can be calculated to an accuracy of better than $10^{-3}$ (Thalman and Volkamer, 2013). $f_{\mathrm{c}}^{i}$ is a unitless correction factor that accounts for differences in profile shape and absorption wavelength between $\mathrm{O}_{4}$ and the trace gas of interest. It is defined as

$f_{\mathrm{c}}^{i}=\frac{f_{\mathrm{O}_{4}}}{f_{\mathrm{TG}}^{i} \cdot f_{\mathrm{WL}}}$.

The retrieval calculates $f_{\mathrm{c}}^{i}$ iteratively based on changes in $f_{\mathrm{TG}}^{i}$ according to

$f_{\mathrm{TG}}^{i}=\frac{\sum_{n_{\mathrm{L}}}^{n_{\mathrm{U}}} c_{n}^{i} \cdot \mathrm{dBAMF}_{n}}{c_{n_{\text {instr }}^{i}}^{i} \cdot \sum_{n_{\mathrm{L}}}^{n_{\mathrm{U}}} \mathrm{dBAMF}_{n}}$, where $\mathrm{dBAMF}_{n}$ is the dBox-AMF value in layer $n$. The initial iteration, $i=0$, assumes that the trace gas concentration $c_{n}^{0}$ is constant inside $S$. Subsequent iterations calculate $f_{\mathrm{TG}}^{i}$ and $f_{\mathrm{c}}^{i}$ using prior iteration $c_{n}^{i}$ values retrieved during aircraft ascent or descent. Concentration values between maximum aircraft altitude and $n_{\mathrm{U}}$ are interpolated using relative profile information from an atmospheric model. Convergence is typically achieved after the third iteration $(i=2)$ (see Fig. S2.)

The factor $f_{\mathrm{O}_{4}}$ accounts for the $\mathrm{O}_{4}$ profile shape effect on the scaling of the dBox-AMFs. It is calculated as

$f_{\mathrm{O}_{4}}=\frac{\sum_{0}^{N} c\left(\mathrm{O}_{4}\right)_{n} \cdot \mathrm{d} h \cdot \mathrm{dBAMF}_{n}}{c\left(\mathrm{O}_{4}\right)_{n_{\text {instr }}} \cdot \sum_{n_{\mathrm{L}}}^{n_{\mathrm{U}}} \mathrm{d} h \cdot \mathrm{dBAMF}_{n}}$.

All Box-AMFs are simulated for the wavelength of the trace gas of interest (see Table 1). The difference in absorption wavelength between the measured $\mathrm{O}_{4}$ and trace gas dSCD is accounted for by $f_{\mathrm{WL}}$ :

$f_{\mathrm{WL}}=\frac{a_{n}(\lambda)}{\mathrm{O}_{4} \mathrm{dSCD}}+b_{n}(\lambda)+c_{n}(\lambda) \cdot \mathrm{O}_{4} \mathrm{dSCD}$,

where $a_{n}(\lambda), b_{n}(\lambda)$ and $c_{n}(\lambda)$ are wavelength-dependent second-order polynomial coefficients for each altitude layer $n$. The polynomial coefficients are derived by first simulating $\mathrm{O}_{4} \mathrm{dSCD}$ for different aerosol extinction profiles at all $\mathrm{O}_{4}$ and trace gas wavelengths, and then applying altitudedependent fits to $\mathrm{O}_{4}$ dSCDs at each trace gas wavelength plotted over $\mathrm{O}_{4}$ dSCDs at the nearest $\mathrm{O}_{4}$ wavelength. See Sect. 3.1.2 for further details.

The volume mixing ratio at instrument altitude, $\mathrm{VMR}_{n_{\text {instr }}}$, is derived by dividing the final iteration $c_{n \text { instr }}^{i}$ derived with Eq. (1) by the air number density of $n_{\text {inst }}$. All VMRs in this study are expressed in pptv, i.e., parts per trillion $\left(1 \times 10^{-12}\right)$ by volume.

Since more than half of the $\mathrm{O}_{4}$ concentration profile is located below $4 \mathrm{~km}$, the suitability of $\mathrm{O}_{4}$ as scaling factor with increasing altitude needs to be assessed. Figure 2 investigates the altitude-dependent sensitivity of $\mathrm{O}_{4}$ measurements. Panel a shows EA $0^{\circ}$ SCD and dSCD measurements simulated for a Rayleigh atmosphere for a solar zenith angle (SZA) range between 0 and $70^{\circ}$. The reference spectrum to create dSCDs has a SZA of $25^{\circ}$ and is from $14.75 \mathrm{~km}$ altitude, which is the maximum altitude for this study and representative of the range of altitudes covered during the TORERO project. Values above $15 \mathrm{~km}$ are included for reference, since some other research aircraft have the capability to access these higher altitudes. The comparatively strong $\mathrm{O}_{4}$ absorption allows the significant detection of $\mathrm{O}_{4} \mathrm{dSCDs}$ of up to $20 \mathrm{~km}$ at $477 \mathrm{~nm}$ and up to $18 \mathrm{~km}$ at $360 \mathrm{~nm}$, assuming a detection limit of $2 \times 10^{41} \mathrm{molec}^{2} \mathrm{~cm}^{-5}$ and $5 \times 10^{41} \mathrm{molec}^{2} \mathrm{~cm}^{-5}$, respectively, which means that $\mathrm{O}_{4}$ detection is not a limiting factor for the altitude range of this study. Moreover, Fig. $2 \mathrm{~b}$ shows the fraction of the $\mathrm{O}_{4}$ signal coming from outside the sensitive range $S$, for both 
Table 1. RTM settings.

\begin{tabular}{ll}
\hline Parameter & RTM value \\
\hline Wavelength & $350 \mathrm{~nm}(\mathrm{BrO}) ; 428 \mathrm{~nm}(\mathrm{IO}) ; 447 \mathrm{~nm}\left(\mathrm{NO}_{2}\right) ; 360$ and $477 \mathrm{~nm}\left(\mathrm{O}_{4}\right)$ \\
\hline SZA & $0,10,25,40,50,60,70^{\circ}$ \\
SRAA & $90^{\circ}$ \\
EA & $0,10,90^{\circ}$ \\
Altitude & EA $0^{\circ}: 0.1 \mathrm{~km}, 0.25-14.75 \mathrm{~km}$ in $0.5 \mathrm{~km}$ increments \\
& EA $10^{\circ}: 11.25,12.25,13.25,14.25,14.75 \mathrm{~km}$ \\
& EA $90^{\circ}: 0.1,4.25,7.75,11.25,12.25 \mathrm{~km}$ \\
Ground albedo & $350 / 360 \mathrm{~nm}: 0.05,428-477 \mathrm{~nm}: 0.08$ \\
g-parameter* & marine: $0.75 ;$ urban: $0.69 ;$ mixed: 0.72 \\
SSA* & marine: $0.98 ;$ urban: $350 / 360 \mathrm{~nm} ; 0.92,428-477 \mathrm{~nm}: 0.94 ;$ mixed: 0.96 \\
\hline
\end{tabular}

* Settings based on Dubovik et al. (2002).

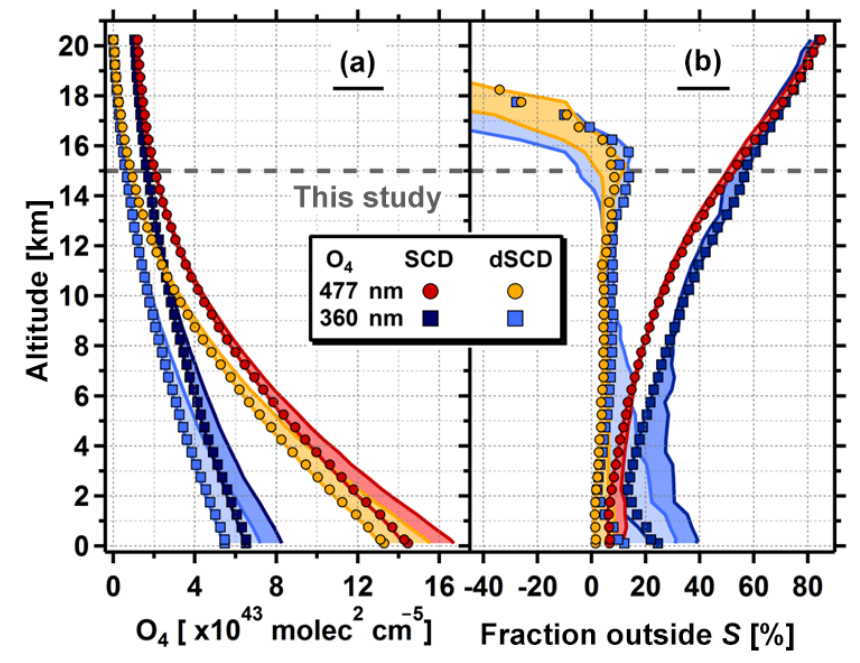

Figure 2. Sensitivity of EA $0^{\circ} \mathrm{O}_{4}$ measurements at 360 and $477 \mathrm{~nm}$ with $\mathrm{SZA}=25^{\circ}$ (markers) and $\mathrm{SZA}=0-70^{\circ}$ (shadings). (a) $\mathrm{O}_{4}$ $\mathrm{SCD}$ and dSCDs values. The reference spectrum to create dSCDs is an EA $10^{\circ}$ spectrum from $14.25 \mathrm{~km}$ with $\mathrm{SZA}=25^{\circ}$. (b) Fraction of the total SCD/dSCD coming from outside the sensitive range $S$.

SCDs and dSCDs. On average only $10 \%$ of the dSCD signal originates from outside $S$, which makes the $\mathrm{O}_{4}$ dSCDs very suitable for use as scaling factor. Increasing fractions below $5 \mathrm{~km}$ at $360 \mathrm{~nm}$ are due to stronger Rayleigh scattering, which decreases the vertical extent of $S$ and the magnitude of the dBox-AMF forward peak. Even though $\mathrm{O}_{4} \mathrm{SCDs}$ are not directly used for the parameterization retrieval, the increase of outside contributions to the total $\mathrm{O}_{4} \mathrm{SCD}$ with altitude are an indication of the increased error sensitivity of the $\mathrm{O}_{4}$ dSCD towards inaccurate subtraction of outside contributions by the reference spectrum. We conclude that using measured $\mathrm{O}_{4}$ dSCDs as an aerosol scaling factor is limited to altitudes below $15 \mathrm{~km}$. For further discussion on the $\mathrm{O}_{4}$ dSCD error see Sect. 4.

\subsection{Correction of dSCD contributions from outside $S$}

The accuracy of $c_{n_{\text {instr }}}$ retrieved with Eq. (1) depends on the availability of a reference spectrum to cancel out dSCD contributions from above and below the sensitive range $S$. Ideally each set of EA $0^{\circ} \mathrm{dSCD}$ measurements has a reference recorded under the same atmospheric conditions. Actual field data might not contain a sufficient amount of suitable references for a variety of reasons. Therefore a dSCD correction term is included, $\mathrm{dSCD}_{\mathrm{c}}^{i}$, to account for contributions from outside $S$ that are not canceled out by the reference. For example strong profile gradients, or a difference in SZA between reference and measurement, can lead to significant EA $0^{\circ}$ dBox-AMFs values outside $S$ and thus create significant dSCD contributions from outside $S$. Particularly for absorbers with a large stratospheric VCD, a small change in SZA can significantly affect the dSCD value. The additive term $\mathrm{dSCD}_{\mathrm{c}}^{i}$ is separated in a tropospheric and stratospheric contribution term:

$\mathrm{dSCD}_{\mathrm{c}}^{i}=\mathrm{dSCD}_{\text {trop }}^{i}+\mathrm{dSCD}_{\text {strat }}$.

The tropospheric slant column correction, $\mathrm{dSCD}_{\text {trop }}^{i}$, is defined as

$$
\begin{array}{r}
\mathrm{dSCD}_{\text {trop }}^{i}=-\mathrm{d} h \cdot \sum_{n_{0}}^{n_{\max }} c_{n}^{i} \cdot \mathrm{dBAMF}_{n} \\
\text { for } i>0 \text { and } n \neq n_{\mathrm{L}} \ldots n_{\mathrm{U}}
\end{array}
$$

$\mathrm{dSCD}_{\text {trop }}^{i}$ is calculated from the surface to maximum aircraft altitude (layer $n_{\max }$ ) for all $n$ below $n_{\mathrm{L}}$ and above $n_{\mathrm{U}}$ using prior iteration $c_{n}^{i}$ values retrieved during aircraft ascent or descent. For $i=0, c_{n}^{0}$ is set to zero and hence $\mathrm{dSCD}_{\text {trop }}^{i}$ is zero. Note that the distinction between tropospheric and stratospheric contributions is based on aircraft maximum altitude here, not on actual tropopause height.

The stratospheric correction is calculated from layer $n_{\max }$ to $N$, i.e., the top of the atmosphere, and is applied to absorbers with a significant stratospheric VCD - here, $\mathrm{BrO}$ and 


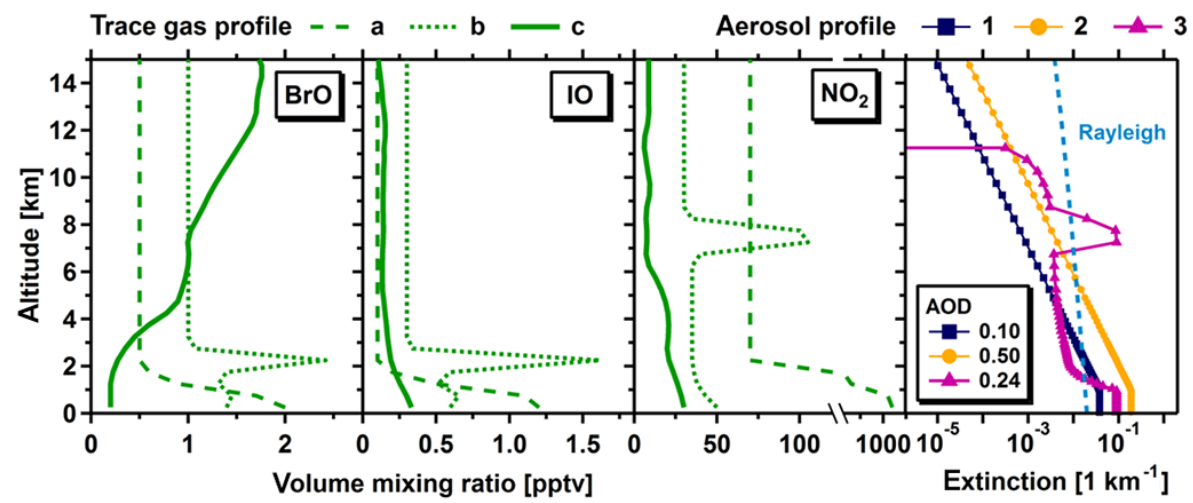

Figure 3. Trace gas volume mixing ratio and aerosol extinction profiles used to simulate dSCD data for sensitivity studies.

$\mathrm{NO}_{2}$. If $n_{\max }$ did not cover most of the troposphere, the inclusion of $\mathrm{dSCD}_{\text {strat }}$ also for tropospheric absorbers might become necessary. The stratospheric correction is based on upward-looking EA $10^{\circ}$ dSCD measurements at $n_{\max }$. We use EA $10^{\circ}$ spectra instead of zenith spectra because EA $10^{\circ}$ measurements have a greater photon flux and therefore have a better signal to noise ratio, which is particularly helpful for measurements above $10 \mathrm{~km}$ aircraft altitude and below $400 \mathrm{~nm}$, where the zenith sky becomes increasingly dark. Further, the EA $10^{\circ}$ geometry is more sensitive towards the atmosphere above $n_{\max }$ than a zenith spectrum. The stratospheric slant column correction term, $\mathrm{dSCD}_{\text {strat }}$, is then defined as

$$
\begin{aligned}
\mathrm{dSCD}_{\text {strat }} & =\operatorname{VCD}\left(t_{0}\right)_{\text {strat }} \cdot \operatorname{AMF}\left(t_{0}\right)_{\text {ref }_{\text {strat }}} \\
& -\operatorname{VCD}(t)_{\text {strat }} \cdot \operatorname{AMF}(t)_{\text {ref }_{\text {strat }}}-\Delta \operatorname{dSCD}(t),
\end{aligned}
$$

where $\operatorname{AMF}\left(t_{0}\right)_{\text {ref }_{\text {strat }}}$ is the air mass factor (AMF) of the zenith reference, recorded at time $t_{0}$, which was used to analyze both EA $0^{\circ}$ and $\operatorname{EA} 10^{\circ} \operatorname{dSCDs} ; \operatorname{AMF}(t)_{\text {ref }_{\text {strat }}}$ is the air mass factor for a zenith reference at the same reference altitude, but calculated with the SZA at time $t$, i.e., the time of measurement; $\operatorname{VCD}\left(t_{0}\right)_{\text {strat }}$ and $\operatorname{VCD}(t)_{\text {strat }}$ are the stratospheric VCDs at the time of reference and measurement respectively. $\triangle \mathrm{dSCD}(t)$ accounts for remaining stratospheric contributions from outside $S$ at time $t$ and is defined as

$$
\begin{aligned}
\Delta \operatorname{dSCD}(t) & =\operatorname{dAMF}\left(t, \operatorname{EA~} 0^{\circ}\right)_{\text {above }} \cdot \operatorname{VCD}(t)_{\text {strat }} \\
& \cdot \frac{\operatorname{AMF}\left(t, \operatorname{EA~} 10^{\circ}\right)_{\text {strat }}-\operatorname{AMF}\left(t, \operatorname{EA~} 10^{\circ}\right)_{\text {in }}}{\operatorname{AMF}\left(t, \operatorname{EA~} 10^{\circ}\right)_{\text {above }}-\operatorname{AMF}\left(t, \operatorname{EA~} 10^{\circ}\right)_{\text {in }}},
\end{aligned}
$$

where the subscript "in" refers to layers between $n_{\max }$ and $n_{\mathrm{U}}$ and "above" to layers $\left(n_{\mathrm{U}}+1\right)$ to $N$. AMFs and dAMFs are the sum over Box-AMFs/dBox-AMFs scaled by the trace gas profile. The profile information comes from an atmospheric model.

$\operatorname{VCD}\left(t_{0}\right)_{\text {strat }}$ is derived by dividing the $\mathrm{EA} 10^{\circ} \mathrm{dSCD}$ at time $t_{0}$ by $\mathrm{dAMF}\left(t_{0}, \mathrm{EA} 10^{\circ}\right)_{\text {strat }}$. Contributions from layers below $n_{\max }$ to the EA $10^{\circ} \mathrm{dSCD}$ are assumed to be canceled out by the reference. $\operatorname{VCD}(t)_{\text {strat }}$ at the time of measurement is calculated as EA $10^{\circ} \mathrm{dSCD}(t)+\mathrm{SCD}\left(t_{0}\right)_{\text {ref }_{\text {strat }}}$ divided by $\operatorname{AMF}\left(t, \text { EA } 10^{\circ}\right)_{\text {strat }}$. Here, SCD and AMF are used instead of $\mathrm{ASCD}$ and $\mathrm{dAMF}$ to avoid increased uncertainties created by the division of two small numbers. The stratospheric amount contained in the reference, $\operatorname{SCD}\left(t_{0}\right)_{\text {ref }_{\text {strat }}}$, can easily be calculated from $\operatorname{VCD}\left(t_{0}\right)_{\text {strat }}$. When reference and measurement are close in time, $\mathrm{dSCD}_{\text {strat }}$ approaches $\Delta \mathrm{dSCD}(t)$.

\section{Application to synthetic data}

In order to define filter criteria for conditions under which the parameterization retrieval is suitable for field data, a series of sensitivity studies were conducted, using synthetic data. The synthetic data set consists of $\mathrm{BrO}, \mathrm{IO}$ and $\mathrm{NO}_{2}$ dSCDs simulated for different trace gas and aerosol extinction profiles (Fig. 3). Details on the setup are provided in Sect. 3.1. BrO and $\mathrm{NO}_{2}$ are both gases for which a significant portion of the total VCD resides in the stratosphere. IO, $\mathrm{CHOCHO}$ and $\mathrm{HCHO}$ are mostly tropospheric absorbers, for which IO is discussed here as an example. The parameterization retrieval is first tested on trace gas dSCDs simulated for a Rayleigh atmosphere followed by a study on how the VMR retrievals of the same trace gas profiles are affected by different aerosol extinction profiles.

\subsection{Setup}

\subsubsection{Trace gas and aerosol profiles}

Vertical trace gas profiles of $\mathrm{BrO}, \mathrm{IO}$ and $\mathrm{NO}_{2}$ as well as aerosol extinction profiles used to simulate $\mathrm{dSCD}$ data are shown in Fig. 3. There are three different profiles for each trace gas, named a, b and c. The a profiles peak strongly in the boundary layer and have a constant mixing ratio throughout the troposphere above. The $\mathrm{NO}_{2}$ a profile is selected to represent a polluted boundary layer. All $\mathrm{b}$ profiles exhibit an elevated layer. The IO $b$ profile is based on TORERO measurements near the coast of Antofagasta, Chile, where an IO layer around $2 \mathrm{~km}$ altitude was observed (see also Fig. 7). The $\mathrm{NO}_{2}$ 
b profile overlaps with the aerosol extinction layer of extinction profile 3 , simulating an elevated pollution layer. $\mathrm{BrO}$ and IO c profiles are smoothed TORERO campaign averages for the tropics based on initial parameterization runs (this work). The $\mathrm{NO}_{2}$ c profile is a case study from TORERO research flight (RF) 12 as published in Volkamer et al. (2015). Tropospheric VCDs from the surface to $18 \mathrm{~km}$ for a, b and c profiles are $1.4 \times 10^{13}, 2.4 \times 10^{13}$ and $1.7 \times 10^{13} \mathrm{molec} \mathrm{cm}^{-2}$ for $\mathrm{BrO}, 5.0 \times 10^{12}, 8.6 \times 10^{12}$ and $3.4 \times 10^{12} \mathrm{molec} \mathrm{cm}^{-2}$ for IO and $42.5 \times 10^{14}, 8.0 \times 10^{14}$ and $2.7 \times 10^{14}$ molec cm $^{-2}$ for $\mathrm{NO}_{2}$, respectively. Stratospheric profiles for $\mathrm{BrO}$ and $\mathrm{NO}_{2}$ are based on Realtime Air Quality Modeling System (RAQMS) (Pierce et al., 2003, 2007) for the TORERO study area with $\mathrm{VCD}_{\text {strat }}=1.1 \times 10^{13}$ and $1.3 \times 10^{15}$ molec cm$^{-2}$ for $\mathrm{BrO}$ and $\mathrm{NO}_{2}$ respectively (see Fig. $\mathrm{S} 3$ for profile shape). Profiles were created by averaging and smoothing 30 stratospheric profiles, 5 each from RF01, RF04, RF05, RF12, RF14 and RF17, chosen from flight periods with a consistent tropopause between 17 and $18 \mathrm{~km}$. IO profile concentrations are 0 above $18 \mathrm{~km}$. The aerosol extinction profiles vary in shape, absolute values and composition. Profiles 1 through 3 (Fig. 3) are assumed to represent a clean marine (1), a polluted urban (2) and a semi-polluted (3) environment. The latter consists of marine aerosols in the boundary layer and an urban pollution layer aloft. Profile 1 is similar to extinction we found over pristine ocean during the TORERO project. Profiles 2 and 3 are constructed specifically for the sensitivity studies here to investigate the effects of higher aerosol optical depth (AOD) (1) and lofted pollution (2). Details on the representation of aerosol in the RTM are given in the following section and Table 1.

\subsubsection{Radiative transfer modeling}

All Box-AMFs used in this study are calculated with McArtim (Deutschmann et al., 2011), which is a fully spherical Monte Carlo radiative transfer model. Table 1 provides a summary of RTM settings that were used to compute BoxAMFs for the sensitivity studies. The SZA is varied between 0 and $70^{\circ}$, while the solar relative azimuth angle (SRAA) is kept constant at $90^{\circ}$. All model calculations are performed on a $0.5 \mathrm{~km}$ vertical grid up to $19 \mathrm{~km}$, which is representative of the vertical resolution of our TORERO AMAX-DOAS measurements. EA $0^{\circ}$ measurements are simulated for $0.1 \mathrm{~km}$ and from 0.25 to $14.75 \mathrm{~km}$ in $0.5 \mathrm{~km}$ steps. For zenith spectra, the reference altitude, $h_{\text {ref }}$, is varied between 0.1 and $12.25 \mathrm{~km}$ (see Table 1). Above $12.5 \mathrm{~km}$, the zenith sky is considered too dark to obtain high-quality spectra. EA $10^{\circ}$ reference spectra are simulated for altitudes between 11.25 and $14.75 \mathrm{~km}$ (see Table 1). Reference selection is further discussed in Sect. 3.1.3. The model wavelengths for which Box-AMFs are calculated are selected to match the center wavelength of individual trace gas DOAS fitting windows (Volkamer et al., 2015; Wang et al., 2015), i.e., $350 \mathrm{~nm}$ for $\mathrm{BrO}, 428 \mathrm{~nm}$ for IO, $447 \mathrm{~nm}$ for $\mathrm{NO}_{2}$ and 360 and $477 \mathrm{~nm}$ for $\mathrm{O}_{4}$. The model atmosphere is set up to represent conditions over a tropical ocean as found during TORERO. It includes profiles of ozone $\left(\mathrm{VCD}=7.0 \times 10^{18} \mathrm{molec}\right.$ $\left.\mathrm{cm}^{-2} / 260.2 \mathrm{DU}\right), \mathrm{H}_{2} \mathrm{O} \quad\left(\mathrm{VCD}=1.79 \times 10^{23}\right.$ molec $\left.\mathrm{cm}^{-2}\right)$, $\mathrm{NO}_{2} \quad\left(\mathrm{VCD}=2.76 \times 10^{16}\right.$ molec $\left.\mathrm{cm}^{-2}\right)$ and $\mathrm{O}_{4} \quad(\mathrm{VCD}=$ $1.39 \times 10^{43}$ molec $\left.^{2} \mathrm{~cm}^{-5}\right)$. The $\mathrm{O}_{4}$ profile is corrected for oxygen displacement by water vapor, because the very high water mixing ratios found in the tropical marine boundary layer can decrease collocated $\mathrm{O}_{4}$ concentrations by up to $5 \%$ (Thalman and Volkamer, 2013; Spinei et al., 2015). Surface temperature, pressure and water mixing ratio are $300.2 \mathrm{~K}$, 1010.5 mbar and $3.1 \%$ respectively. Trace gas, temperature and pressure profiles were created by averaging and smoothing 30 individual profiles, 5 each from RF01, RF04, RF05, RF12, RF14 and RF17. Stratospheric ozone and tropospheric $\mathrm{NO}_{2}$ profiles are from RAQMS. For ozone flight periods with a consistent tropopause between 17 and $18 \mathrm{~km}$ are chosen, and for $\mathrm{NO}_{2}$ areas with pristine background air. Tropospheric ozone, $\mathrm{H}_{2} \mathrm{O}$, temperature and pressure are from aircraft in situ measurements and averaged over the same periods as model profiles. Aerosols are included using extinction profiles (Fig. 3), single scattering albedo (SSA) and the g-parameter as representation for the aerosol phase function (Henyey and Greenstein, 1941). Values for SSA and g-parameter are chosen based on Fig. 1 and Table 1 in Dubovik et al. (2002). To simulate trace gas and $\mathrm{O}_{4} \mathrm{SCDs}$ at other wavelengths, aerosol extinction profiles are scaled from $477 \mathrm{~nm}$ assuming an Ångström exponent of one. DSCDs are created using references as described below (Sect. 3.1.3). In order to get the wavelength and altitude-dependent fit coefficients that define $f_{\mathrm{WL}}$ (Eq. 5), $\mathrm{O}_{4}$ dSCDs simulated for all extinction profiles are separated by altitude layers $n$. For each $n$, respective $\mathrm{O}_{4} \mathrm{dSCDs}$ at 447 and $428 \mathrm{~nm}$ are each plotted over $\mathrm{O}_{4} \mathrm{dSCDs}$ at $477 \mathrm{~nm}$ and fitted with a second-order polynomial. The same is done for $\mathrm{O}_{4} \mathrm{dSCDs}$ at $350 \mathrm{~nm}$, but plotted over $\mathrm{O}_{4} \mathrm{dSCDs}$ at $360 \mathrm{~nm}$. The resulting fit parameters are stored in a lookup table and applied in Eq. (5) during the VMR retrieval to interpolate the measured $\mathrm{O}_{4}$ dSCDs in Eq. (1). The same process is applied to interpolate Rayleigh Box-AMFs from 477 to 447 and $428 \mathrm{~nm}$, and from 360 to $350 \mathrm{~nm}$, in order to save RTM computation time. For example, for a near-real-time application of the parameterization retrieval during a field project, a significant amount of computation time can be saved, when for each research flight Box-AMFs along the flight track are calculated at two $\mathrm{O}_{4}$ wavelengths, instead of at all trace gas wavelengths.

\subsubsection{Reference spectra}

For our sensitivity studies, $\mathrm{BrO}$ and $\mathrm{NO}_{2}$ are analyzed with a zenith reference (EA 90 ${ }^{\circ}$ ). Since the sky becomes increasingly dark with altitude, upward-looking EA $10^{\circ}$ spectra from aircraft maximum altitude are a light-strong alternative for absorbers without significant stratospheric VCDs. $\mathrm{O}_{4}$ and $\mathrm{IO}$ are therefore analyzed with high-altitude EA $10^{\circ}$ ref- 
erences. A further advantage of EA $10^{\circ}$ references is that in the presence of aerosols EA $10^{\circ}$ Box-AMFs from highaltitude spectra resemble EA $0^{\circ}$ Box-AMFs outside $S$ more closely than those of zenith references, thus canceling out distributions from outside $S$ more accurately (Volkamer et al., 2015). Altitudes for both zenith and EA $10^{\circ}$ references are listed in Table 1. For IO, trace gas and $\mathrm{O}_{4}$ references are identical. When retrieving $\mathrm{BrO}$ and $\mathrm{NO}_{2}, \mathrm{O}_{4}$ is analyzed with an EA $10^{\circ}$ reference from aircraft maximum altitude, here $14.75 \mathrm{~km}$. Trace gas and $\mathrm{O}_{4}$ references have the same SZA. For a more detailed discussion on suitable references for $\mathrm{BrO}, \mathrm{IO}$ and $\mathrm{NO}_{2}$ see Volkamer et al. (2015).

\subsection{Sensitivity studies}

SCDs were simulated for all trace gas and aerosol extinction profiles shown in Fig. 3 and for settings summarized in Table 1. Parameters of interest that are varied are SZA, $\triangle \mathrm{SZA}$, i.e., the SZA difference between EA $0^{\circ}$ and reference measurement, and the reference altitude $h_{\text {ref }}$. Trace gas dSCDs were created by permuting through every reference for each combination of trace gas and aerosol profiles, for a total of 2940 different full profile case studies. For the VMR retrieval only dSCDs larger than $1.5 \times 10^{13} \mathrm{molec} \mathrm{cm}^{-2}$ for $\mathrm{BrO}$, larger than $2 \times 10^{12}$ molec $\mathrm{cm}^{-2}$ for IO and larger than $2 \times 10^{14}$ molec cm ${ }^{-2}$ for $\mathrm{NO}_{2}$ are considered as significant, and smaller dSCDs are filtered. These limits are based on typical fit uncertainties for the University of Colorado (CU) AMAX-DOAS instrument as reported among other trace gases in Volkamer et al. (2015), i.e., $1.3 \times 10^{13}$ molec cm $^{-2}$ for BrO, $2.1 \times 10^{12}$ molec cm $^{-2}$ for IO and $1.5 \times 10^{14}$ molec cm $\mathrm{cm}^{-2}$ for $\mathrm{NO}_{2}$. For trace gases with stratospheric VCDs, the maximum SZA is limited to $60^{\circ}$, creating a total of 2160 different full profile case studies for $\mathrm{BrO}$ and $\mathrm{NO}_{2}$. IO dSCD data above $h_{\text {ref }}$ are removed for test cases where $h_{\text {ref }}$ is below aircraft maximum altitude. Further filtering is based on the results of the sensitivity studies and discussed in Sect. 3.2.2.

\subsection{1 $\mathrm{VMR}_{\text {para }}$ in a Rayleigh atmosphere}

Figure 4 presents a summary of VMR retrieval results from trace gas dSCDs simulated for a Rayleigh atmosphere for $735 \mathrm{IO}$ and $540 \mathrm{BrO}$ and $\mathrm{NO}_{2}$ profile case studies and for $i=2$ (see Fig. S4 for a comparison of $i=0$ and $i=2$ ). Results are displayed separately for each trace gas and profile shape. All retrieved $\mathrm{VMR}_{\text {para }}$ are binned by EA $0^{\circ}$ instrument altitude (see Table 1). For each altitude, the average and standard deviation of $\mathrm{VMR}_{\text {para }}$ is calculated and plotted in the individual left panels of Fig. 4 together with the original trace gas profile as reference. The green shading indicates $\pm 0.5 \mathrm{pptv}$ for $\mathrm{BrO}, \pm 0.05 \mathrm{pptv}$ for $\mathrm{IO}$ and $\pm 10 \mathrm{pptv}$ for $\mathrm{NO}_{2}$. To get further information on the distribution of retrieved VMRs, ratios of $\mathrm{VMR}_{\text {para }}$ over true VMR, $\mathrm{VMR}_{\text {true }}$, are calculated. These ratios are plotted as vertically resolved
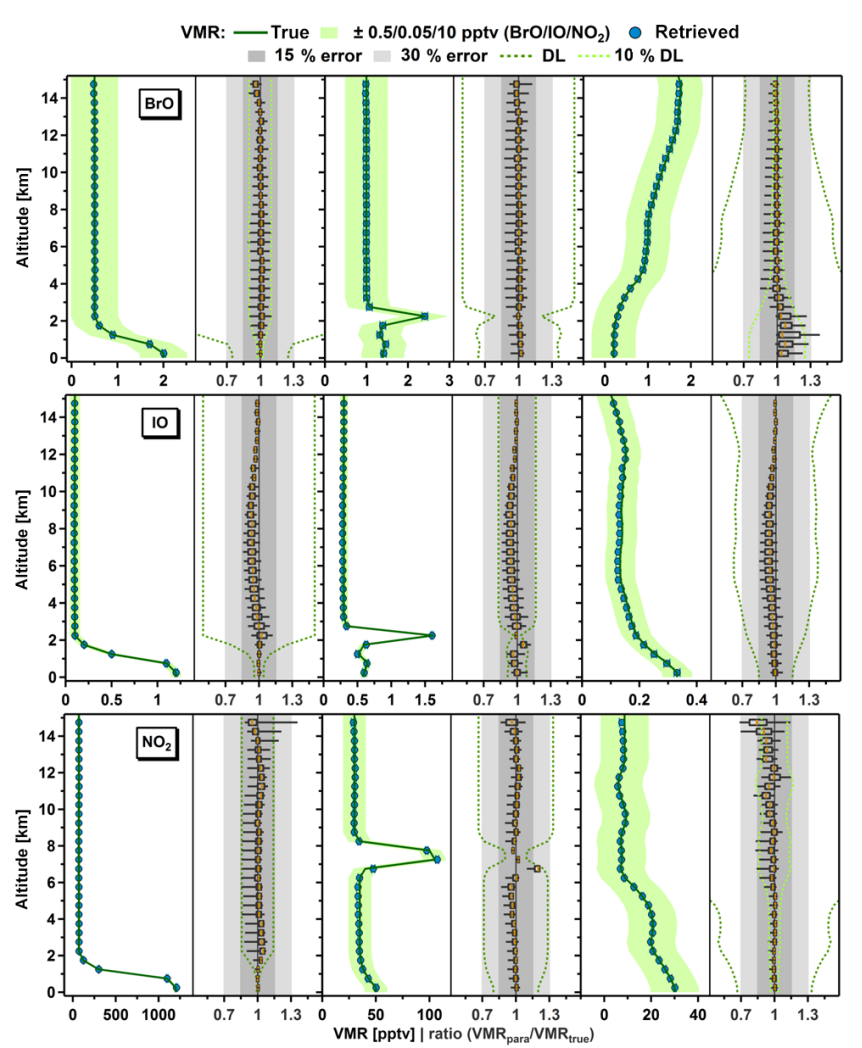

Figure 4. Retrieved VMR for $\mathrm{BrO}$ (top), $\mathrm{IO}$ (middle) and $\mathrm{NO}_{2}$ (bottom) a, b and c profiles (left to right) using dSCD data simulated for a Rayleigh atmosphere. Individual left panels show $\mathrm{VMR}_{\text {para }}$ average and standard deviation. Original trace gas profiles are included as reference and green shading denotes individual trace gas VMR error bounds. Right panels display altitude-resolved whisker plots of the ratios of $\mathrm{VMR}_{\text {para }}$ over $\mathrm{VMR}_{\text {true, }}$, showing the median (orange) and 5, 25, 75 and 95 percentiles. Grey shaded areas indicate 15 and $30 \%$ error; green dashed lines show trace gas detection limits.

whiskers in the individual right panels of Fig. 4. Whiskers denote 5, 25, 75 and 95 percentiles. A ratio of 1 means $\mathrm{VMR}_{\text {para }}$ is retrieved without error. Grey shaded areas indicate 15 and $30 \%$ error respectively. Dark green dashed lines show the equivalent of $\pm 0.5,0.05$ and 10 pptv for $\mathrm{BrO}$, IO and $\mathrm{NO}_{2}$, respectively, calculated by adding or subtracting the respective amount from the true profile before division by the true profile. The light green line represents the dark green line multiplied by 0.1 . The agreement between retrieved and true VMRs is excellent for all trace gases and profile shapes. Even 5 and 95 percentile whiskers fall within the $30 \%$ error margin or better. These results demonstrate the accuracy of the stratospheric correction for $\mathrm{BrO}$ and $\mathrm{NO}_{2}$. For $\mathrm{BrO}$ and $\mathrm{NO}_{2} \mathrm{c}$ profiles the true mixing ratio falls within 0.5 and 10 pptv respectively. The comparison of the 5 and 95 percentiles indicates a slight low bias of the retrieved VMRs for both $\mathrm{BrO}$ and $\mathrm{NO}_{2}$ across all profile shapes. This bias is primarily caused by negative $\Delta$ SZAs, i.e., the SZA of the 
Table 2. VMR retrieval results for synthetic data.

\begin{tabular}{llrrrr}
\hline Trace gas & Atmosphere & Mean & Standard deviation & Within error ${ }^{\mathrm{a}}(\%)$ & Within DL ${ }^{\mathrm{b}}(\%)$ \\
\hline $\mathrm{BrO}$ & Rayleigh & 0.99 & 0.06 & 100 & 100 \\
$\mathrm{BrO}$ & Aerosol 1 & 1.00 & 0.11 & 99.9 & 99.9 \\
$\mathrm{BrO}$ & Aerosol 2 & 1.01 & 0.14 & 99.3 & 97.8 \\
$\mathrm{BrO}$ & Aerosol 3 & 1.04 & 0.15 & 99.7 & 99.6 \\
$\mathrm{IO}$ & Rayleigh & 0.97 & 0.05 & 100 & 99.4 \\
$\mathrm{IO}$ & Aerosol 1 & 0.92 & 0.07 & 98.8 & 90.8 \\
$\mathrm{IO}$ & Aerosol 2 & 0.88 & 0.09 & 92.8 & 83.8 \\
$\mathrm{IO}$ & Aerosol 3 & 0.90 & 0.13 & 91.9 & 85.0 \\
$\mathrm{NO}$ & Rayleigh & 0.99 & 0.07 & 99.5 & 96.7 \\
$\mathrm{NO}_{2}$ & Aerosol 1 & 1.00 & 0.09 & 98.7 & 87.9 \\
$\mathrm{NO}_{2}$ & Aerosol 2 & 1.00 & 0.14 & 94.9 & 85.3 \\
$\mathrm{NO}_{2}$ & Aerosol 3 & 1.02 & 0.14 & 95.8 & 78.7 \\
\hline
\end{tabular}

a \pm 0.5 pptv or $30 \%$ for $\mathrm{BrO}, \pm 0.05$ pptv or $20 \%$ for IO, \pm 10 pptv or $30 \%$ for $\mathrm{NO}_{2} \cdot{ }^{\mathrm{b}} \pm 0.5 \mathrm{pptv}$ for $\mathrm{BrO}, \pm 0.05$ pptv for IO, \pm 10 pptv for $\mathrm{NO}_{2}$.

reference is higher than the SZA of the measurement. The impact of $\triangle \mathrm{SZA}<0^{\circ}$ can be seen in Fig. S4, which shows select $\mathrm{VMR}_{\text {para }}$ data color coded by SZA, $\triangle \mathrm{SZA}$ and $h_{\text {ref. }}$. SZA here and in the following always refers to the SZA of the measurement spectrum, not the reference. For $i=0$ the general trend in the retrieved VMRs is that the relative deviation from the true profile increases with increasing SZA. For $\triangle \mathrm{SZA}<0, \mathrm{VMR}_{\text {para }}$ values underestimate the true profile. This is similarly true for reference spectra recorded at low altitudes, e.g., $0.1 \mathrm{~km}$ for zenith spectra $\left(\mathrm{BrO}\right.$ and $\left.\mathrm{NO}_{2}\right)$ and $11.25 \mathrm{~km}$ for $\mathrm{EA}^{\circ} 10$ spectra (IO). The iterative corrections applied during the VMR retrieval significantly improve final results, especially for $\mathrm{BrO}$. The retrieval of IO VMRs is very robust and shows no strong sensitivities to variations in SZA, $\triangle \mathrm{SZA}$ or $h_{\text {ref }}$, regardless of iteration status. The final $\mathrm{VMR}_{\text {para }}$ results for $i=2$ are within $\pm 0.5 \mathrm{pptv}$ for $\mathrm{BrO}, \pm 0.05$ pptv for $\mathrm{IO}$ and $\pm 10 \mathrm{pptv}$ for $\mathrm{NO}_{2}$. While the errors created by a changing SZA and low $h_{\text {ref }}$ are essentially eliminated by the iterative corrections, a low bias caused by $\triangle \mathrm{SZA}<0^{\circ}$ remains for $\mathrm{BrO}$ and $\mathrm{NO}_{2}$. For example, the VMR ratio of the $\mathrm{BrO}$ c profile at $11.25 \mathrm{~km}$ altitude with $\triangle \mathrm{SZA}=-40^{\circ}$ and $h_{\text {ref }}=0.1 \mathrm{~km}$ is 0.87 , while the ratio at the same altitude with $\triangle \mathrm{SZA}=15^{\circ}$ and $h_{\text {ref }}=0.1 \mathrm{~km}$ is 1.01. Corresponding ratio values for the $\mathrm{NO}_{2} \mathrm{~b}$ profile are 0.85 and 0.99 . For all 540 Rayleigh profile cases, $100 \%$ of $\mathrm{BrO} \mathrm{VMR}_{\text {para }}$ data are retrieved within $\pm 0.5 \mathrm{pptv}$ of the true profile. Where the true profile falls below $0.5 \mathrm{pptv}, 100 \%$ is retrieved within 0.5 pptv. For $\mathrm{NO}_{2} 96.7 \%$ of $\mathrm{VMR}_{\text {para }}$ data are reproduced within \pm 10 pptv and $100 \%$ of VMRs below 10 pptv are retrieved within the limit. Where $\mathrm{VMR}_{\text {para }}$ is outside \pm 10 pptv of $\mathrm{VMR}_{\text {true }}, 85.8 \%$ are retrieved within $30 \%$ of $\mathrm{VMR}_{\text {true }}$. For all $735 \mathrm{IO}$ profile cases, $99.4 \%$ of $\mathrm{VMR}_{\text {para }}$ data are retrieved within \pm 0.05 pptv. A summary of these results is included in Table 2 below. Based on these results, we define $0.5,0.05$ and 10 pptv for $\mathrm{BrO}, \mathrm{IO}$ and $\mathrm{NO}_{2}$, respectively, as (1) suitable detection limits and (2) in combination with a $20 \%$ (IO) and $30 \%$ (BrO) error suitable error bounds for the parameterization method in a Rayleigh atmosphere.

\subsection{2 $\mathrm{VMR}_{\text {para }}$ in aerosol atmospheres}

The presence of aerosol in the atmosphere changes BoxAMFs; this is accounted for in the parameterization retrieval by using a measured $\mathrm{O}_{4}$ dSCD in Eq. (1) to scale Rayleigh modeled Box-AMFs. In comparison to results from a Rayleigh atmosphere, the quality of retrieved VMRs in atmospheres with aerosol shows a stronger and more complex dependency on SZA, $\Delta$ SZA and $h_{\text {ref }}$ Therefore Fig. 5 presents results for select case studies to highlight these specific dependencies. Summary figures for individual extinction profiles in the style of Fig. 4 are provided in the Supplement (Figs. S5-S7) and discussed in Sect. 4.3. Figure 5 shows $\mathrm{VMR}_{\text {para }}$ plotted over $\mathrm{VMR}_{\text {true }}$ for select SZA, $\triangle \mathrm{SZA}$

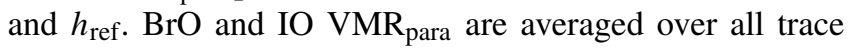
gas and aerosol profiles. $\mathrm{NO}_{2}$ results are averaged over $\mathrm{NO}_{2}$ $\mathrm{b}$ and c profiles (Fig. 3) and all aerosol profiles. Averages of the $\mathrm{NO}_{2}$ a profile are shown in Fig. S8. A total of eight case studies are displayed in panels a through $\mathrm{h}$. Panel columns alternate between low and high SZA $\left(25\right.$ and $\left.60^{\circ}\right)$. Rows highlight the dependency on $\triangle \mathrm{SZA}$ for $\triangle \mathrm{SZA}=0,35$ and $-15^{\circ}$, in combination with a variation of $h_{\text {ref. Panels a, b, e }}$ and $\mathrm{f}$ show results with $h_{\text {ref }}=4.25 \mathrm{~km}$ for $\mathrm{BrO}$ and $\mathrm{NO}_{2}$ and $h_{\text {ref }}=14.75 \mathrm{~km}$ for IO, which are considered to be optimal references for our case studies. Panels $\mathrm{c}$ and d display the effect of using a zenith reference from $0.1 \mathrm{~km}$, while panels $g$ and $h$ show results for a high zenith reference. For a direct comparison, IO data in panels $\mathrm{c}, \mathrm{d}, \mathrm{g}$ and $\mathrm{h}$ are also analyzed with zenith references. $\mathrm{VMR}_{\text {para }}$ data for each panel summarize over nine profile cases for $\mathrm{BrO}$ and $\mathrm{IO}$ and over six cases for $\mathrm{NO}_{2}$. Whisker plots show 5, 25, 75 and 95 percentiles for binned VMR data. VMRs for $\mathrm{BrO}$ are binned in 0.5 pptv intervals and for $\mathrm{IO}$ in 0.25 pptv intervals. $\mathrm{NO}_{2}$ bins 

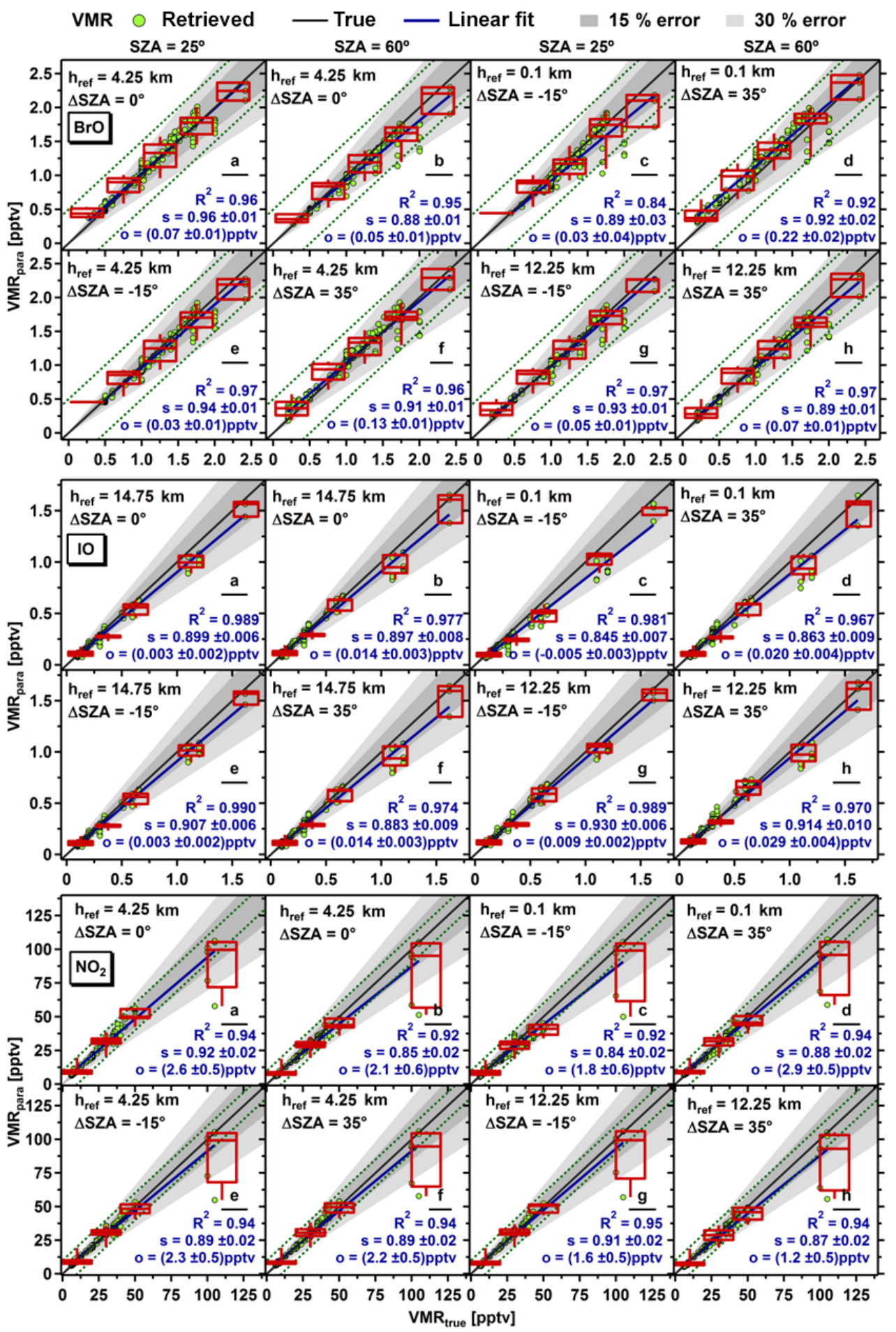

Figure 5. $\mathrm{VMR}_{\text {para }}$ over $\mathrm{VMR}_{\text {true }}$ for $\mathrm{BrO}$ (top), $\mathrm{IO}$ (middle) and $\mathrm{NO}_{2}$ (bottom) averaged over all $\mathrm{BrO}$ and IO trace gas profiles, over $\mathrm{NO}_{2} \mathrm{~b}$ and c profiles and over all aerosol profiles for select SZA, $\triangle \mathrm{SZA}$ and $h_{\text {ref }}$. The panel columns alternate between low $\left(\mathrm{SZA}=25^{\circ}\right)$ and high SZA $\left(\mathrm{SZA}=60^{\circ}\right)$. The whisker plots show the median and $5,25,75$ and 95 percentiles for binned VMR $\mathrm{Vara}_{\text {data. }}$ Grey shaded areas indicate 15 and $30 \%$ error. Linear fits and fit parameter (s: slope; o: offset) are included in each panel. 
are defined as follows: $20 \mathrm{pptv}$ intervals from $0-80 \mathrm{pptv}$, then 80-150, 150-400 and 400-1300 pptv. Linear fits to $\mathrm{VMR}_{\text {para }}$ and respective fit parameters, "s" for slope and "o" for offset, are included in each panel. Grey shadings indicate 15 and $30 \%$ error respectively.

\section{Effect of SZA}

VMR retrievals for $\mathrm{BrO}$ and $\mathrm{NO}_{2}$ show a stronger dependency on SZA than those of IO, which can be expected for trace gases with a significant stratospheric VCD. For $\mathrm{SZA}=25^{\circ}$ and the optimal $h_{\text {ref }}$, i.e., panels a and e, $\mathrm{BrO}$ and $\mathrm{NO}_{2}$ correlation slopes are on average $0.95 \pm 0.01$ and $0.905 \pm 0.015$. Offsets are all below the respective detection limits of $0.5 \mathrm{pptv}$ for $\mathrm{BrO}$ and $10 \mathrm{pptv}$ for $\mathrm{NO}_{2}$ and $R^{2}$ values are 0.96 (a) $/ 0.97$ (e) for $\mathrm{BrO}$ and 0.94 for a and e for $\mathrm{NO}_{2}$. Results for $\mathrm{SZA}=25^{\circ}$ and $h_{\text {ref }}=12.25 \mathrm{~km}$ (panel g) are comparable for both $\mathrm{BrO}$ and $\mathrm{NO}_{2}$. Higher SZAs increase the stratospheric contribution to the measured dSCDs, which creates a stronger sensitivity to errors in the stratospheric correction. $\mathrm{BrO}$ and $\mathrm{NO}_{2} \mathrm{VMR}_{\text {para }}$ for $\mathrm{SZA}=60^{\circ}$ with $h_{\text {ref }}=4.25 \mathrm{~km}$ and $12.25 \mathrm{~km}$ (panels b, f and $\mathrm{h}$ ) show somewhat lower correlation slopes that are on average $0.89 \pm 0.02$ for $\mathrm{BrO}$ and $0.87 \pm 0.02$ for $\mathrm{NO}_{2}$, but offsets remain below respective detection limits and average $R^{2}$ values are still high with $0.96 \pm 0.01$ for $\mathrm{BrO}$ and $0.93 \pm 0.01$ for $\mathrm{NO}_{2}$. When looking at the $\mathrm{NO}_{2}$ a profile only (Fig. S8), then the linear fits are strongly driven by the very high boundary layer VMRs, which is why the $\mathrm{NO}_{2}$ data set is separated by profile shape here. For the $\mathrm{NO}_{2}$ a profile the SZA dependence is much more pronounced. For optimal and high references, correlation slopes are around 0.91 for $\mathrm{SZA}=25^{\circ}$ and around 0.81 for $\mathrm{SZA}=60^{\circ}$. In contrast, when using a high-altitude reference spectrum for IO, panels a, b, e through h, correlation slopes are within \pm 2 percentage points and corresponding offsets are $0.003-0.029 \mathrm{pptv}$, which is well below the 0.05 pptv detection limit. $R^{2}$ values are between 0.970 and 0.990 .

\section{Effect of $\Delta$ SZA and $h_{\text {ref }}$}

The impact of $\Delta$ SZA and $h_{\text {ref }}$ depends on the combination of both quantities. When using either the optimal or high reference altitude, i.e., panels $a, b$, e through $h$, the VMR results for all trace gases are dominated by the SZA effect, as discussed above. Varying $\triangle \mathrm{SZA}$ between 0,35 and $-15^{\circ}$ for a constant SZA, i.e., comparing panels a, e, g and panels $\mathrm{b}, \mathrm{f}, \mathrm{h}$, leads to differences in correlation slopes that are within \pm 0.02 . Interestingly, a $\triangle \mathrm{SZA}$ of zero does not always provide the best result because a larger difference in SZA between reference and measurements can actually increase the accuracy of the correction term $f_{\mathrm{c}}$ (Eq. 1). Overall, the combination of $\triangle \mathrm{SZA}=-15$ or $35^{\circ}$ with a zenith reference from the boundary layer $(0.1 \mathrm{~km}$ altitude) yields the largest deviations of $\mathrm{VMR}_{\text {para }}$ from $\mathrm{VMR}_{\text {true }}$ for all trace gases. For example, in panel c, the correlation slope drops to 0.89 with $R^{2}=0.84$ for $\mathrm{BrO}$, the slope is 0.845 with $R^{2}=0.981$ for IO and the slope is 0.84 with $R^{2}=0.92$ for $\mathrm{NO}_{2}$. The $\mathrm{NO}_{2}$ a profile shows comparable behavior in panel d, with a slope of 0.77 (Fig. S8). Overall the observed trends are significantly reflected in correlation slopes and $R^{2}$ values, while offsets are typically very small and well below $50 \%$ of the individual trace gas detection limit. Slopes for optimal and high reference spectra indicate that on average $\mathrm{VMR}_{\text {para }}$ are retrieved within 10 to $15 \%$ of $\mathrm{VMR}_{\text {true }}$ with tight correlations, i.e., $R^{2}$ values of 0.92 and better. Based on the combined effect of low $h_{\text {ref }}$ and $\Delta \mathrm{SZA}<0^{\circ}$ an additional filter for the parameterization retrieval is introduced: VMR retrieval of trace gases with stratospheric VCDs are limited to $\triangle \mathrm{SZA}>-25^{\circ}$ for $h_{\text {ref }}<2 \mathrm{~km}$. Following the error discussion, results of the full set of sensitivity studies are discussed in Sect. 4.3.

\section{Error analysis and discussion}

\subsection{Retrieval error}

The underlying assumption of Eq. (1) is that dSCD $\approx \mathrm{dSCD}(S)$, i.e., that the $\mathrm{EA} 0^{\circ} \mathrm{dSCD}$ measurement quantifies the trace gas slant column in $S$ (see Sect. 2.1 and Fig. 1). How well this assumption holds true depends on the choice of reference spectrum and the accuracy of the iterative correction term $\mathrm{dSCD}_{\mathrm{c}}^{i}$ introduced in Eqs. (6) through (9). The same assumption underlies the measured $\mathrm{O}_{4}$ dSCDs. Further error sources are insufficient correction of the $\mathrm{O}_{4}$ and trace gas profile shapes based on Eqs. (3) and (4), and errors caused by the wavelength interpolation of measured $\mathrm{O}_{4}$ dSCDs based on Eq. (5). The synthetic data set allows the quantification of individual error sources and the overall error. The following error terms are being analyzed here: the error of $\mathrm{dSCD}_{c}^{i}$ and the errors of $f_{\mathrm{TG}}^{i}, f_{\mathrm{O}_{4}}$ and $f_{\mathrm{WL}}$. The magnitude of each error is defined as the ratio of calculated value over true value, which returns 1 when the error is 0 . The $\mathrm{dSCD}_{\mathrm{c}}^{i}$ error ratio, $\Delta \mathrm{dSCD}_{\mathrm{c}}^{i}$, is defined as $\mathrm{dSCD}-\mathrm{dSCD}_{\mathrm{c}}^{i}$, divided by $\operatorname{dSCD}(S)$. For the $f_{\mathrm{TG}}$ error ratio, $\Delta f_{\mathrm{TG}}^{i}$, the value of $f_{\mathrm{TG}}^{i}$ calculated with Eq. (3) is divided by the true $f_{\mathrm{TG}}$, i.e., using Eq. (3) and replacing $c_{n}^{i}$ with the true trace gas concentration. The $f_{\mathrm{O}_{4}}$ error ratio, $\Delta f_{\mathrm{O}_{4}}$, summarizes the error caused by applying $\mathrm{O}_{4} \mathrm{dSCDs}$ as scaling factor for Rayleigh modeled Box-AMFs. Based on Eq. (1), it is defined as

$\Delta f_{\mathrm{O}_{4}}=\frac{c\left(\mathrm{O}_{4}\right)_{n_{\text {instr }}}}{\mathrm{O}_{4} \mathrm{dSCD}} \cdot f_{\mathrm{O}_{4}} \cdot \sum_{n_{\mathrm{L}}}^{n_{\mathrm{U}}} \mathrm{d} h \cdot \operatorname{dBAMF}(\text { aer })_{n}$,

where $\mathrm{dBAMF}(\mathrm{aer})$ are the Box-AMFs simulated for the specific aerosol profile. The $f_{\mathrm{WL}}$ error ratio, $\Delta f_{\mathrm{WL}}$, quantifies the ratio of wavelength shifted $\mathrm{O}_{4} \mathrm{dSCDs}$ using Eq. (5) over $\mathrm{O}_{4} \mathrm{dSCDs}$ directly simulated at the respective trace gas wavelength. Note that these error ratios are not random errors, but express a systematic deviation from the true value, which can be calculated for each retrieved VMR data point. 
The total error ratio, $\Delta$ total, is defined as the deviation of the calculated trace gas concentration from the true trace gas concentration and is thus identical to $\mathrm{VMR}_{\text {para }}$ over $\mathrm{VMR}_{\text {true }}$. It can be directly calculated from the above introduced error ratios using Eq. (1) as follows:

$$
\frac{\mathrm{VMR}_{\text {para }}}{\mathrm{VMR}_{\text {true }}}=\Delta \text { total }=\Delta \mathrm{dSCD}_{\mathrm{c}}^{i} \cdot \frac{\Delta f_{\mathrm{O}_{4}}}{\Delta f_{\mathrm{TG}}^{i} \cdot \Delta f_{\mathrm{WL}}} .
$$

Note that this notation is chosen because it explicitly accounts for the fact that individual component errors can compensate each other. All error calculations are performed for $i=2$. For Rayleigh cases both $\Delta f_{\mathrm{O}_{4}}$ and $\Delta f_{\mathrm{WL}}$ are 1 .

Figure 6 shows examples of error ratios plotted over altitude and separated by trace gas and aerosol extinction profiles with $\mathrm{SZA}=25^{\circ}, \Delta \mathrm{SZA}=25^{\circ}$ and $h_{\text {ref }}=4.25 \mathrm{~km}$ for $\mathrm{BrO}$ and $\mathrm{NO}_{2}$ and $h_{\text {ref }}=14.75 \mathrm{~km}$ for IO. Results are shown for $\mathrm{BrO} c, \mathrm{IO} b$ and $\mathrm{NO}_{2}$ b profiles. Error ratios for all trace gas profiles are included in the Supplement (Figs. S9-S11). In Figs. 6 and S9-S11, $\Delta f_{\mathrm{TG}}^{i}$ and $\Delta f_{\mathrm{WL}}$ are plotted inverse in accordance with the fact that they enter the denominator in Eq. (11).

\subsection{1 $\Delta \mathrm{dSCD}_{c}^{i}$}

Error ratios from $\mathrm{dSCD}_{\mathrm{c}}^{i}$ are the dominating error source in a Rayleigh atmosphere and remain a comparatively large error source for atmospheres with aerosols for all trace gases. The magnitude of $\Delta \mathrm{dSCD}_{\mathrm{c}}^{i}$ is a direct reflection of how well the assumption $\mathrm{dSCD} \approx \mathrm{dSCD}(S)$ holds true. At the selected solar and measurement geometry conditions, $\mathrm{dSCD}_{\text {trop }}^{i}$ and $\mathrm{dSCD}_{\text {strat }}$ are comparable for both the $\mathrm{BrO} \mathrm{c}$ profile and the $\mathrm{NO}_{2} \mathrm{~b}$ profile, with $\sim 1 \times 10^{12}$ molec $\mathrm{cm}^{-2}$ for $\mathrm{BrO}$ and $\sim 2 \times 10^{14}$ molec $\mathrm{cm}^{-2}$ for $\mathrm{NO}_{2}$, which means that the combined tropospheric and stratospheric $\mathrm{dSCD}_{\mathrm{c}}^{i}$ correction is not dominated by either part of the profile. Stronger deviations are correlated with the absolute trace gas concentration and higher aerosol extinction. For example, for the $\mathrm{BrO} \mathrm{c}$ profile in the boundary layer, $\Delta \mathrm{dSCD}_{\mathrm{c}}^{i}$ ranges between 1.5 and 2.7. Here the true profile is $<0.25 \mathrm{pptv}$, which means that the signal from inside $S$ contributing to the EA $0^{\circ}$ dSCD measurements is very small. The dashed lines in Fig. 6 show the equivalent of $\pm 0.5 \mathrm{pptv} \mathrm{BrO}$ or the scaled equivalent of $\pm 0.05 \mathrm{pptv}$ as reference. $\Delta$ total for all cases is well below the detection limit of \pm 0.5 pptv. However, the steep increase in deviations for all error ratios for the $\mathrm{BrO}$ c profile below $4 \mathrm{~km}$ indicates that the accuracy of $\mathrm{VMR}_{\text {para }}$ declines with decreasing dSCDs and that using a detection limit is justified. A strong $\triangle \mathrm{dSCD}_{\mathrm{c}}^{i}$ deviation from 1 caused by the elevated aerosol layer of aerosol 3 (Fig. 3) is seen for IO and $\mathrm{BrO}$. Here dSCDs are overcorrected, but this error is partially compensated by too-low $f_{\mathrm{O}_{4}}$ values. Interestingly, $\Delta \mathrm{dSCD}_{\mathrm{c}}^{i}$ is smaller for the $\mathrm{NO}_{2} \mathrm{~b}$ profile, where the $\mathrm{NO}_{2}$ profile itself has an elevated layer (Fig. 3).
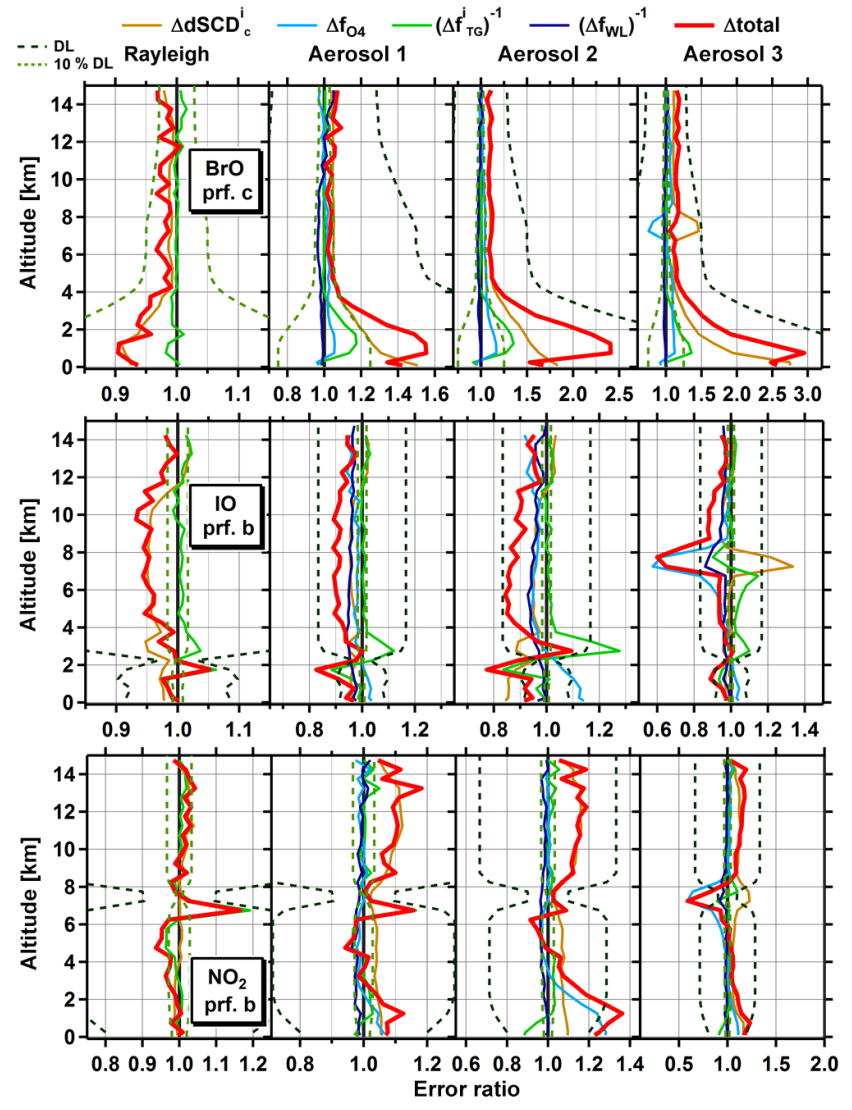

Figure 6. Total error ( $\Delta$ total) and error ratios of individual components of Eq. (1) for $\mathrm{BrO}$ c profile (top), IO b profile (middle) and $\mathrm{NO}_{2}$ b profile (bottom) for Rayleigh and aerosol case studies with $\mathrm{SZA}=25^{\circ}$ and $\triangle \mathrm{SZA}=25^{\circ}$. Reference altitude is 4.25 for $\mathrm{BrO}$ and $\mathrm{NO}_{2}$ and $14.75 \mathrm{~km}$ for IO. Green dashed lines show trace gas detection limits. Note the different $x$ axis scaling for individual panels.

\subsection{2 $\Delta f_{\mathrm{TG}}^{i}$}

$f_{\mathrm{TG}}^{i}$ corrects for trace gas gradients within $S$. Hence deviations from one of $\Delta f_{\mathrm{TG}}^{i}$ are directly related to the trace gas profile shape. In a Rayleigh and sub-Rayleigh atmosphere (see Fig. 3) $\Delta f_{\mathrm{TG}}^{i}$ is on average around $\pm 2 \%$ and deviates only significantly from 1 where the $\mathrm{VMR}_{\text {true }}$ profile has strong concentration gradients, e.g., around the IO layer between 2 and $3 \mathrm{~km}$ in the IO b profile, around $7 \mathrm{~km}$ for the $\mathrm{NO}_{2} \mathrm{~b}$ profile, or around $2 \mathrm{~km}$ for all trace gas a profiles (Figs. S9-S11). The magnitude of the deviation depends on the aerosol extinction. For example, the peak in $\Delta f_{\mathrm{TG}}^{i}$ at $1.75 \mathrm{~km}$ in the IO b profile changes from 1.12 to $1.27 \mathrm{be}-$ tween aerosol 1 and 2, where both extinction profiles have the same shape, but where aerosol 2 has a higher extinction ( 0.11 vs. $0.02 \mathrm{~km}^{-1}$ at $1.75 \mathrm{~km}$ altitude). This is similarly true for the $\mathrm{NO}_{2}$ a profile (Fig. S11) at $0.1 \mathrm{~km}$, where $\Delta f_{\mathrm{TG}}^{i}$ increases from 1.24 to 1.44 between aerosol 1 and 2 (extinctions at $0.1 \mathrm{~km}$ are $\left(0.188\right.$ vs. $\left.0.037 \mathrm{~km}^{-1}\right)$. The overlap of trace gas 
and aerosol extinction gradients as well as higher absolute extinction increases $\Delta f_{\mathrm{TG}}^{i}$ deviations from 1, which is typically the case for trace gas and aerosol profiles that represent polluted environments (Sect. 3.1).

\subsection{3 $\Delta f_{\mathrm{O}_{4}}$}

The $f_{\mathrm{O}_{4}}$ error ratio generally follows the shape and magnitude of the extinction profile as can be expected. For $\mathrm{NO}_{2}$ at $447 \mathrm{~nm}$ and $\mathrm{IO}$ at $428 \mathrm{~nm}, f_{\mathrm{O}_{4}}$ tends to overestimate the extinction in the boundary layer $\left(\Delta f_{\mathrm{O}_{4}}>1\right)$ and slightly underestimate the extinction in the free troposphere $\left(\Delta f_{\mathrm{O}_{4}}<1\right)$, where the aerosol extinction is sub-Rayleigh. For $\mathrm{BrO}$, the effect is reversed in the boundary layer and not significant in the troposphere. This result is caused by the differences in the wavelength dependency of Rayleigh and aerosol extinction. Box-AMFs scale with light path length. In the presence of aerosol, the total extinction is determined by Rayleigh and aerosol extinction. Since Rayleigh extinction scales with $\lambda^{-4}$ and the aerosol extinction in our sensitivity study scales with $\lambda^{-1}$, the (strong) aerosol extinction in the boundary layer at 447 and $428 \mathrm{~nm}$ has a comparatively stronger effect at wavelengths above $400 \mathrm{~nm}$ than at $350 \mathrm{~nm}$ where $\mathrm{BrO}$ is measured. The tendency to underestimate extinction in the troposphere above $400 \mathrm{~nm}$ is caused by multiple scattering. While the presence of aerosol typically decreases the light path length at instrument altitude, and hence the Box-AMFs within $S$, increased scattering in aerosol layers below or above instrument altitude can lead to increased contributions from outside $S$ to the measured $\mathrm{O}_{4} \mathrm{dSCD}$. Thus the measured $\mathrm{O}_{4}$ dSCD leads to the underestimation of the real extinction. This effect is amplified for the aerosol layer around $7 \mathrm{~km}$ of aerosol profile 3 , since enhanced photon back scatter from the boundary layer and the elevated aerosol layer increases the outside contributions to the $\mathrm{O}_{4}$ dSCD measurements inside the layer further, which leads to $\Delta f_{\mathrm{O}_{4}}$ values as low as 0.59 at $447 \mathrm{~nm}\left(\mathrm{NO}_{2}\right), 0.58$ at $428 \mathrm{~nm}$ (IO) and 0.75 at $350 \mathrm{~nm}(\mathrm{BrO})$. Interestingly, $\triangle \mathrm{dSCD}_{\mathrm{c}}^{i}$ inside the elevated aerosol layer is overestimated at all wavelengths, with a compensating effect on $\Delta$ total.

\subsection{4 $\Delta f_{\mathrm{WL}}$}

The error created by the wavelength interpolation of measured $\mathrm{O}_{4}$ dSCDs is comparatively small. It increases with larger wavelength shifts, e.g., for IO, where $\mathrm{O}_{4}$ dSCDs are shifted from 477 to $428 \mathrm{~nm}$. The $f_{\mathrm{WL}}$ error ratio shows no significant altitude dependence and is typically smaller than $5 \%$. The largest $\Delta f_{\mathrm{WL}}$ deviation from 1 is found at $7.25 \mathrm{~km}$ altitude for IO and aerosol 3, inside the elevated aerosol layer, with $\Delta f_{\mathrm{WL}}=0.86$. This larger deviation is caused by defining the polynomial coefficients used in Eq. (5) as average over all extinction profiles. The reduction of EA $0^{\circ}$ $\mathrm{O}_{4}$ dSCDs at different wavelengths is not a linear function of extinction, and interpolation parameters at the altitude of the elevated aerosol layer are biased low by averaging $\mathrm{O}_{4}$ dSCDs from aerosol profile 3 with $\mathrm{O}_{4}$ dSCDs simulated for the sub-Rayleigh extinction of aerosols 1 and 2 at the same altitude. If the polynomial coefficients were generated using only aerosol profile 3 , the same $\Delta f_{\mathrm{WL}}$ would increases to 0.92 . Notably, the elevated pollution layer is a unique case, and affects only a small number of IO and $\mathrm{NO}_{2} \mathrm{VMR}_{\text {para }}$ data within a $1.5 \mathrm{~km}$ altitude range (see also discussion in Sect. 4.3.1).

\subsection{Other error sources}

Other errors affecting the accuracy of VMR $\mathrm{V}_{\text {para }}$ are RTM errors and uncertainties in the atmospheric model profiles used to interpolate retrieved trace gas profiles above aircraft maximum altitude. The RTM error encompasses the statistical error of simulating individual photon paths used to calculate the Box-AMFs and the error created by wavelength shifting Box-AMFs (see Sect. 3.1.2). McArtim is initialized with $10^{5}$ photons, which reduces the statistical error to below $0.5 \%$ (see also Spinei et al., 2015). Table S1 in the Supplement gives fit coefficients of linear fits to shifted Box-AMF data over original data. Slopes are 0.999 with a $1-2 \times 10^{-4}$ error and offsets are $\leq 0.003$. Atmospheric model profiles are used to interpolate trace gas profiles above aircraft maximum altitude and calculate stratospheric AMFs. Here, only the relative profile shape is important, since absolute $\mathrm{VCD}$ values are canceled out during the AMF calculation. Stratospheric profile shapes of $\mathrm{BrO}$ and $\mathrm{NO}_{2}$ are well constrained by models; therefore the error based on profile shape is assumed to be very small and accounted for by the error bounds.

\subsection{Summary and overall error}

The sensitivity studies in a Rayleigh atmosphere have shown that the parameterization retrieval works very well across a wide range of measurement geometries. VMR retrievals in aerosol atmospheres are more sensitive to SZA and choice of reference spectrum. In Figs. S5-S7 VMR para $_{\text {results for }}$ aerosol atmospheres are displayed using the style introduced in Fig. 4; i.e., left panels show mean and standard deviation of $\mathrm{VMR}_{\text {para }}$ and right panels show altitude-resolved whisker plots of the ratio of $\mathrm{VMR}_{\text {para }}$ over $\mathrm{VMR}_{\text {true }}$. Note that in contrast to Fig. 5 the additional $\triangle \mathrm{SZA}$ filter is applied here, where for $\mathrm{BrO}$ and $\mathrm{NO}_{2}$ the VMR retrieval is limited to $\Delta \mathrm{SZA}>-25^{\circ}$ when $h_{\text {ref }}<2 \mathrm{~km}$. Compared to a Rayleigh atmosphere the $\mathrm{VMR}_{\text {para }}$ distribution around the mean has a larger spread. Where the aerosol extinction is sub-Rayleigh (see Fig. 3), the mean stays close to 1 for $\mathrm{BrO}$ and $\mathrm{NO}_{2}$. The effect of SZA, $\triangle$ SZA and $h_{\text {ref }}$ discussed above is captured in the whisker percentiles. For IO the mean tends to deviate from 1 between 2 and $10 \mathrm{~km}$, which is the effect of $\Delta \mathrm{dSCD}_{\mathrm{c}}^{i}$ that is intensified by $\Delta f_{\mathrm{WL}}$ and $\Delta f_{\mathrm{O}_{4}}$ for atmospheres with aerosol as shown in Fig. 6. However, most VMR $\mathrm{V}_{\text {para }}$ data are still retrieved within error bounds. Table 2 summarizes the 
mean and $1 \sigma$ standard deviation of the ratio $\mathrm{VMR}_{\text {para }}$ over $\mathrm{VMR}_{\text {true }}$, for each trace gas separated by atmospheres. The column "within error" states the fraction of $\mathrm{VMR}_{\text {para }}$ that is retrieved either within the VMR detection limit or within $30 \%$ for $\mathrm{BrO}$ and $\mathrm{NO}_{2}$ and $20 \%$ for IO. The distinction in percentage is based on the stronger sensitivity to SZA, $\triangle \mathrm{SZA}$ and $h_{\text {ref }}$ for trace gases with stratospheric VCD. After filtering all $\mathrm{VMR}_{\text {para }}$ data are retrieved on average within $10 \%$ of the error bounds or better.

\section{Field data}

When applying the parameterization retrieval to dSCD data from the TORERO measurements, dSCDs have associated measurement errors. To test the effect of dSCD errors, VMRs for all trace gas and aerosol profiles were retrieved, adding or subtracting $1.5 \times 10^{13} \mathrm{molec} \mathrm{cm}^{-2}$ for $\mathrm{BrO}, 2 \times 10^{12}$ molec cm${ }^{-2}$ for IO and $2 \times 10^{14}$ molec cm $^{-2}$ for $\mathrm{NO}_{2}$. The impact on $\mathrm{VMR}_{\text {para }}$ was assessed by adding the error caused by the measurement uncertainty and the parameterization error in quadrature. On average $92.9 \%$ of resulting $\mathrm{VMR}_{\text {para }}$ data are still retrieved within the above defined error bounds. The fit errors for $\mathrm{O}_{4} \mathrm{dSCDs}$ are typically well below $5 \%$, with absolute values $<5 \times 10^{41} \mathrm{molec}^{2} \mathrm{~cm}^{-5}$ at $477 \mathrm{~m}$ and $<1 \times 10^{42} \mathrm{molec}^{2} \mathrm{~cm}^{5}$ at $360 \mathrm{~nm}$, and are accounted for by the error bounds. To avoid uncertainties created by fit errors, measured $\mathrm{O}_{4}$ dSCDs are set equal to Rayleigh modeled dSCDs when their absolute difference is smaller than $5 \times 10^{41} \mathrm{molec}^{2} \mathrm{~cm}^{-5}$ at $477 \mathrm{~m}$ and smaller than $1 \times 10^{42} \mathrm{molec}^{2} \mathrm{~cm}^{-5}$ at $360 \mathrm{~nm}$. The uncertainty in determining $\mathrm{O}_{4} \mathrm{SCD}_{\text {ref }}$ for the absolute scaling of measured $\mathrm{O}_{4}$ dSCDs is essentially canceled out by using dSCDs and considered negligible.

We conclude that $30 \%$ uncertainty for gases with stratospheric VCD contributions, and $20 \%$ for tropospheric absorbers, but no better than 0.5 pptv $\mathrm{BrO}, 10 \mathrm{pptv} \mathrm{NO}_{2}$ and 0.05 pptv IO are suitable error bounds for the parameterization retrieval across different trace gas and aerosol profiles. Errors and sensitivities that arise from strongly changing trace gas VCDs and atmospheric conditions when flying at level altitude will be discussed elsewhere.

\subsubsection{Outliers}

Some $\mathrm{VMR}_{\text {para }}$ data retrieved outside error bounds show significant and systematic deviations from $\mathrm{VMR}_{\text {true }}$. Examples of such outliers in Fig. 5 are the $\mathrm{VMR}_{\text {para }}$ points that deviate by about $0.6 \mathrm{pptv}$ from $\mathrm{VMR}_{\text {true }}$ for $\mathrm{BrO}$ in panel $\mathrm{b}$, deviations of 0.12 pptv from a true VMR of 0.3 pptv for IO in panel $\mathrm{b}$ and deviations of around $50 \mathrm{pptv}$ for true values around 100 pptv for $\mathrm{NO}_{2}$ across all panels. These outliers are not captured by data filtering. This is for example the case for the $\mathrm{IO} b$ profile and aerosol profile 1 (Fig. S5), for $\mathrm{BrO}$ and $\mathrm{NO}_{2}$ a profiles and aerosol 2 (Fig. S6) or for $\mathrm{IO}$ and $\mathrm{NO}_{2}$ b profiles and aerosol profile 3 (Fig. S7). When looking at the trace gas profile shapes of the individual left panels in Figs. S5-S7, it becomes apparent that strong gradients in the trace gas profile can shift the retrieved medians significantly away from 1, with partial or full whiskers exceeding the error bounds. In a Rayleigh atmosphere, similar outliers are seen for $i=0$, but the iterative corrections bring final $\mathrm{VMR}_{\text {para }}$ data well within error bounds (Sect. 3.2.1 and Fig. S4). In the presence of aerosols the iterative corrections fail when trace gas and aerosol extinction gradients overlap or where extinction is high, like in the lofted pollution layer of aerosol profile 3 . These are highly localized effects, but need to be kept in mind when using the parameterization retrieval in areas with strong trace gas and extinction gradients. Under those conditions, OE retrievals are preferred.

\subsubsection{Impact of $\mathrm{SCD}_{\text {ref }}$}

The selection of a suitable reference spectrum is crucial to best fulfilling the approximation $\mathrm{dSCD} \approx \mathrm{dSCD}(S)$, which is applicable for both trace gas and $\mathrm{O}_{4} \mathrm{dSCDs}$. Case study results from Figs. 5 and S8, panels c and d, indicate that the VMR retrieval quality decreases and exhibits a low bias when using a boundary layer zenith reference compared to reference spectra from higher altitudes. This observation is a direct result of $\mathrm{SCD}_{\text {ref }}$ being maximized for a boundary layer zenith spectrum and thus decreasing EA $0^{\circ}$ dSCDs. Measured EA $0^{\circ}$ dSCDs are further decreased for $\triangle \mathrm{SZA}<0^{\circ}$, where the comparatively higher SZA of the reference spectrum increases $\mathrm{SCD}_{\text {ref }}$ even more. For example, for $\mathrm{SZA}=25^{\circ}, \Delta \mathrm{SZA}=-15^{\circ}$ and $h_{\text {ref }}=0.1 \mathrm{~km}$ (Figs. $5 \mathrm{c}$ and S8c), $\mathrm{SCD}_{\text {ref }}$ values averaged over aerosol profiles 1-3 are $3.8 \times 10^{13}$ molec cm $^{-2}$ for the $\mathrm{BrO}$ a profile, $7.6 \times 10^{15}$ molec $\mathrm{cm}^{-2}$ for the $\mathrm{NO}_{2}$ a profile and $7.2 \times 10^{12} \mathrm{molec} \mathrm{cm}^{-2}$ for the IO a profile, compared to $3.2 \times 10^{13}, 6.4 \times 10^{15}$ and $6.1 \times 10^{12}$ molec cm $^{-2}$ for $\mathrm{SZA}=60^{\circ}, \Delta \mathrm{SZA}=35^{\circ}$ and $h_{\text {ref }}=0.1 \mathrm{~km}$ (Figs. $5 \mathrm{~d}$ and $\mathrm{S} 8 \mathrm{~d}$ ) for $\mathrm{BrO}, \mathrm{NO}_{2}$ and $\mathrm{IO}$ respectively. For the optimized conditions, e.g., for $\mathrm{SZA}=25^{\circ}, \Delta \mathrm{SZA}=0^{\circ}$ and $h_{\text {ref }}=4.25 \mathrm{~km} \quad\left(\mathrm{BrO}, \mathrm{NO}_{2}\right)$ or $14.75 \mathrm{~km} \quad$ (IO) (Fig. 5a), $\mathrm{SCD}_{\text {ref }}$ values are $2.5 \times 10^{13}, 3.4 \times 10^{15}$ and $3.9 \times 10^{12}$ molec cm ${ }^{-2}$ for $\mathrm{BrO}, \mathrm{NO}_{2}$ and IO respectively. For $\mathrm{VMR}_{\text {para }}$ data that are not retrieved within error bounds, the ratio of EA $0^{\circ}$ dSCDs over $\mathrm{SCD}_{\text {ref }}$ is typically smaller 2. These findings underline the importance of reference selection and minimizing $\mathrm{SCD}_{\text {ref }}$, as, e.g., pointed out by Volkamer et al. (2015) and Coburn et al. (2016). Volkamer et al. (2015) compared ship-based and airborne MAX-DOAS during TORERO, in a case study where the trace gas profile above the ship was characterized by the aircraft. They found best agreement only when $\mathrm{SCD}_{\text {ref }}$ was accounted for in the ship MAX-DOAS retrievals and showed that the widely accepted assumption of $\mathrm{SCD}_{\text {ref }}=0$ can lead to bias of up to a factor of 2 for partial VCDs as retrieved from the ship. Maximizing knowledge about $\mathrm{SCD}_{\text {ref }}$ can also be actively exploited to extend the information content in ground-based 
MAX-DOAS retrievals of free tropospheric $\mathrm{BrO}$ (Coburn et al., 2016).

Finding a suitable reference for $\mathrm{O}_{4}$ measurements is less straightforward due to the multiple scattering effects described in Sect. 4.1. In fact, using a high-altitude zenith spectrum that typically minimizes $\mathrm{SCD}_{\text {ref }}$ leads here to a much stronger underestimation of extinction in the troposphere up to the point where extinction appears to be lower than that of a pure Rayleigh atmosphere. The key to a suitable $\mathrm{O}_{4}$ reference is finding a reference for which Box-AMFs outside $S$ are most similar to Box-AMFs outside $S$ of the EA $0^{\circ}$ spectrum, without minimizing the EA $0^{\circ} \mathrm{dSCD}$ too strongly. Based on our findings, EA $10^{\circ}$ spectra from aircraft maximum altitude are a good match for these criteria, consistent with our earlier recommendation (Volkamer et al., 2015).

\subsubsection{Optimized observing strategy parameterization retrieval}

As discussed above, minimizing $\mathrm{SCD}_{\text {ref }}$ is the best strategy to minimize $\mathrm{VMR}_{\text {para }}$ errors. Aircraft measurements allow the recording of reference spectra at different geometries and altitudes, which renders AMAX-DOAS particularly suitable for the parameterization retrieval. For unknown trace gas and extinction profile shapes, it is advisable to record several references from different altitude and geometries to not limit the ability to actively minimize $\mathrm{SCD}_{\text {ref }}$.

Data filters that work well for our sensitivity studies are (1) EA $0^{\circ} \mathrm{dSCD}$ limits of $1.5 \times 10^{13} \mathrm{molec}^{-2}$ for $\mathrm{BrO}$, $2 \times 10^{12}$ molec cm ${ }^{-2}$ for IO and $2 \times 10^{14}$ molec cm $^{-2}$ for $\mathrm{NO}_{2}$; (2) SZA limit of $60^{\circ}$ for stratospheric absorbers; and (3) $\triangle$ SZA limit of $-25^{\circ}$ for $h_{\text {ref }}<2 \mathrm{~km}$. Particularly for stratospheric absorbers, $\mathrm{VMR}_{\text {para }}$ are on average retrieved more accurately for $\triangle \mathrm{SZA} \geq 0^{\circ}$. For a changing SZA and/or changing $\mathrm{VCD}_{\text {strat }}$, the stratospheric correction benefits from continuous VCD characterization by $\mathrm{EA} 10^{\circ}$ measurements.

The interpolation parameter for $\mathrm{O}_{4}$ dSCDs used in Eq. (5) need to be created for local conditions. In cases of strongly varying extinctions, interpolation might need to be replaced with a lookup table. For strong gradients in trace gas and/or aerosol extinction, OE retrieval is preferred.

\section{Application to TORERO field data}

During the TORERO field campaign $\mathrm{BrO}, \mathrm{IO}, \mathrm{NO}_{2}$, CHO$\mathrm{CHO}, \mathrm{HCHO}$ and $\mathrm{O}_{4}$ were measured with the CU AMAXDOAS instrument aboard the NSF/NCAR GV aircraft over the tropical Eastern Pacific Ocean. The TORERO field experiment took place in January/February, 2012. Seventeen research flights were conducted over the tropical and subtropical Pacific, based out of Antofagasta, Chile, and San Jose, Costa Rica. Further information on the campaign can be found in Volkamer et al. (2015). In this section, the parameterization retrieval is applied to TORERO field data. First, select $\mathrm{VMR}_{\text {para }}$ profiles are compared with existing $\mathrm{BrO}$, IO and $\mathrm{NO}_{2}$ vertical profiles retrieved by $\mathrm{OE}$ inversion, followed by a discussion of retrieved $\mathrm{BrO}$ and IO VMRs for the whole campaign.

\subsection{AMAX-DOAS measurements and data analysis}

The CU AMAX-DOAS instrument is described in detail elsewhere (Baidar et al., 2013b; Dix et al., 2013; Volkamer et al., 2015). Briefly, the instrument consists of two synchronized spectrograph-detector units (Acton SP2150/PIXIS400B CCD) that simultaneously observed the spectral ranges from 330 to $470 \mathrm{~nm}(0.7 \mathrm{~nm}$ full width half maximum (FWHM) optical resolution) to measure $\mathrm{BrO}, \mathrm{IO}$, $\mathrm{NO}_{2}$ and $\mathrm{O}_{4}$ at $360 \mathrm{~nm}$ and from 440 to $700 \mathrm{~nm}(1.2 \mathrm{~nm}$ FWHM optical resolution) to observe $\mathrm{O}_{4}$ at $477 \mathrm{~nm}$. Telescopes to access forward-, zenith- and nadir-viewing geometries are housed in a heated, wing-mounted pylon. The limb scanning telescope has a vertical dispersion of $0.17^{\circ}$ and is actively angle stabilized to better $0.2^{\circ}$ accuracy in real time. Most limb spectra were recorded with a time resolution of $30 \mathrm{~s}$, which translates to a vertical resolution of $0.5 \mathrm{~km}$ or better for most ascents and descents of the aircraft. BrO, IO, $\mathrm{NO}_{2}$ and $\mathrm{O}_{4}$ dSCDs were derived from scattered sunlight spectra using the DOAS technique (Perner and Platt, 1979; Platt, 1994; Platt and Stutz, 2008) and the WinDOAS software package (Fayt and Van Roozendael, 2001). For further details, see Volkamer et al. (2015). The accuracy of our $\mathrm{O}_{4}$ measurements has been assessed in a pure Rayleigh atmosphere (Spinei et al., 2015) and in the presence of aerosol (Volkamer et al., 2015). We found no need to apply a correction factor to the measured $\mathrm{O}_{4}$ (Wagner et al., 2009; Spinei et al., 2015; Volkamer et al., 2015).

$\mathrm{BrO}, \mathrm{IO}$ and $\mathrm{NO}_{2} \mathrm{dSCD}$ data used for both the $\mathrm{OE}$ and the parameterization retrievals are quality filtered for instrument and data analysis effects as well as cloud filtered. The color ratio of the measured intensities at 477 and $640 \mathrm{~nm}$ is used to identify clouds in the telescope's field of view and in close proximity. Once the color ratio falls below 2.1 for aircraft altitudes above $4 \mathrm{~km}$ and below 1.95 for aircraft altitudes below $4 \mathrm{~km}, \mathrm{dSCD}$ data are filtered. The altitude distinction accounts for the color ratio also being affected by aerosol extinction, which is typically higher closer to the surface. Color ratio thresholds are determined empirically and work well for most TORERO flights. To ensure that only cloudy dSCD data get filtered, the color ratio filter is manually checked for each flight and changed if needed, based on flight video data. The profile case studies discussed in Sect. $\mathbf{5 . 3}$ are predominantly cloud free. 


\subsection{Optimal estimation profiles and parameterization retrieval}

\subsubsection{Optimal estimation}

Concentration profiles for $\mathrm{BrO}, \mathrm{IO}$ and $\mathrm{NO}_{2}$ were retrieved from TORERO data by linear inversion of measured dSCDs using OE. The RTM McArtim was used to calculate weighting functions that serve as $\mathrm{OE}$ input. Radiation fields were constrained by in situ pressure, temperature and water vapor measurements. CU AMAX-DOAS observations of $\mathrm{O}_{4}$ at 360 and $477 \mathrm{~nm}$ were used to determine local aerosol extinction in a first step. Retrieved extinction profiles were then included in the RTM to calculate weighting functions for the inversion. The number of independent concentration points is typically well aligned with the vertical resolution of the inversion. Control over radiative transfer has been demonstrated by comparison with in situ and modeled $\mathrm{H}_{2} \mathrm{O}$ data, with modeled $\mathrm{NO}_{2}$, and comparison with aerosol extinction retrieved from high spectral resolution lidar (HSRL) and from Mie calculations based on aerosol size distributions measured by an in situ ultra-high-sensitivity aerosol spectrometer (UHSAS) (Volkamer et al., 2015).

\subsubsection{Parameterization}

The parameterized retrieval uses an almost identical RTM atmosphere, but pressure, temperature and water vapor data are averaged over each full flight, which saves RTM computation time. This averaging is possible for the TORERO study area, because air masses for each flight are rather homogenous. Reference spectra for both parameterization and OE dSCDs are identical, with one fixed reference per flight. Using a fixed reference is for practical reasons. The number of reference spectra suitable for the parameterization method is limited in the TORERO data set, particularly because zenith references for $\mathrm{BrO}$ and $\mathrm{NO}_{2}$ need to be close in time to the $\mathrm{O}_{4}$ EA $10^{\circ}$ references. Not all flights provide more than one set of suitable reference spectra. To keep results comparable between flights, each flight is analyzed with one fixed reference. Further selection guidelines for references are discussed in Volkamer et al. (2015). Since atmospheric conditions found in the TORERO study area are well represented in the sensitivity studies above, the same BoxAMFs and polynomial coefficients for the interpolation of measured $\mathrm{O}_{4}$ dSCDs are used. Every research flight but one, $\mathrm{RF} 08$, provided atmospheric conditions, where $\mathrm{O}_{4} \mathrm{dSCD}$ measurements from aircraft altitudes above $12 \mathrm{~km}$ could be considered Rayleigh measurements. Typically an upward angle scan covering EA $0,1,2,5$ and $10^{\circ}$ was used to absolutely scale measured $\mathrm{O}_{4}$ dSCDs (see also Spinei et al., 2015). Atmospheric conditions that pass the above introduced cloud filter are instances where the aircraft flies high above low cloud layers or vice versa. A series of preliminary sensitivity studies with cloud layers at different altitudes and trace gas profiles similar to the c profiles here (Fig. 3) has shown that the ratio of measured and modeled $\mathrm{O}_{4}$ dSCDs can serve as indicator for specific cloud situations. When flying above low cloud layers, $\mathrm{VMR}_{\text {para }}$ are typically retrieved within the established error bounds as long as the $\mathrm{O}_{4}$ dSCD ratio stays below 1.15 at $360 \mathrm{~nm}$ and below 1.2 at $477 \mathrm{~nm}$. For ratios between 1.15 and 1.3 at $360 \mathrm{~nm}$ and 1.2 and 1.4 at $477 \mathrm{~nm}$, the measured $\mathrm{O}_{4} \mathrm{dSCD}$ is scaled to the equivalent of a 1.15 and 1.2 ratio respectively. Here, five percentage points are added to the error bound. Data points with higher $\mathrm{O}_{4}$ ratios are filtered. When flying below a cloud cover, most data are retrieved within error bounds as long as the $\mathrm{O}_{4}$ ratio is larger 0.5 . Once it falls below 0.5 and the color ratio is larger 2.8, data are filtered out. All data points within $2 \mathrm{~km}$ of a solid cloud layer are filtered. HSRL data are used to get information on cloud layer heights. Overall, the cloud information gained from the $\mathrm{O}_{4}$ ratios is very consistent with HSRL observations. Figure $\mathrm{S} 12$ provides examples of $\mathrm{O}_{4}$ ratios and HSRL data for different aerosol and cloud scenarios. Note that our cloud handling here is optimized for atmospheric conditions in the TORERO study area. Further sensitivity studies are warranted in other atmospheric settings, e.g., in instances where high aerosol extinction is present at higher altitudes.

Trace gas profile information above aircraft maximum altitude for $\mathrm{BrO}$ and $\mathrm{NO}_{2}$ is taken from RAQMS. Corrections for dSCD contributions from outside $S$ are based on Eqs. (6)(9) for $\mathrm{NO}_{2}$ and IO. In order to calculate $\operatorname{AMF}(t)_{\text {ref }_{\text {strat }}}$ used in Eqs. (8) and (9), $\operatorname{AMF}\left(t_{0}\right)_{\text {ref }_{\text {strat }}}$ is scaled with the stratospheric geometric $\mathrm{AMF}$, i.e., $\mathrm{AMF}=1 / \cos (\mathrm{SZA})$, which saves RTM computation time. Stratospheric BrO VCDs are quantified by RAQMS, since the TORERO data set does not contain a sufficient amount of high signal-to-noise EA $10^{\circ}$ spectra. Maximum $\mathrm{BrO} \mathrm{dSCD}_{\text {strat }}$ (Eq. 8) values are typically around $1-2 \times 10^{13}$ molec $\mathrm{cm}^{-2}$ at $\mathrm{SZA}=60^{\circ}$, which is on the order of the EA $0^{\circ}$ dSCD fit error. Select comparison of stratospheric corrections retrieved from EA $10^{\circ}$ measurements confirm the model-based correction within an $2-3 \times 10^{13}$ molec $\mathrm{cm}^{-2}$ uncertainty created by the EA $10^{\circ}$ dSCD fit error. For $\mathrm{NO}_{2}$, a typical TORERO dSCD $\mathrm{dtrat}_{\text {value }}$ at $60^{\circ} \mathrm{SZA}$ is $1.5-3 \times 10^{15} \mathrm{molec} \mathrm{cm}^{-2}$, which is about a factor of 2-4 higher than a tropospheric EA $0^{\circ}$ dSCDs measured in pristine background air (e.g., $\mathrm{NO}_{2} \mathrm{c}$ profile). Here, our EA $10^{\circ} \mathrm{dSCD}$ fit error of $3-5 \times 10^{14}$ molec cm $^{-2}$ is almost on the same order as the tropospheric EA $0^{\circ}$ dSCDs, underlining the need for a highly accurate characterization of the stratospheric VCD by EA $10^{\circ}$ measurements. Since TORERO specifically targeted very pristine air masses, we refrained from running the $\mathrm{NO}_{2}$ parameterization retrieval on the complete data set and focused instead on select case studies with dSCD $\mathrm{Strat} \ll \mathrm{EA} 0^{\circ} \mathrm{dSCDs}$. For these cases evaluation of $\mathrm{NO}_{2}$ is still possible down to as low as $10 \mathrm{pptv}$, as has been demonstrated in Fig. 10 in Volkamer et al. (2015).

Layer $n_{\max }$, which is the altitude that separates stratospheric and tropospheric corrections (see Sect. 2.2), is set to 

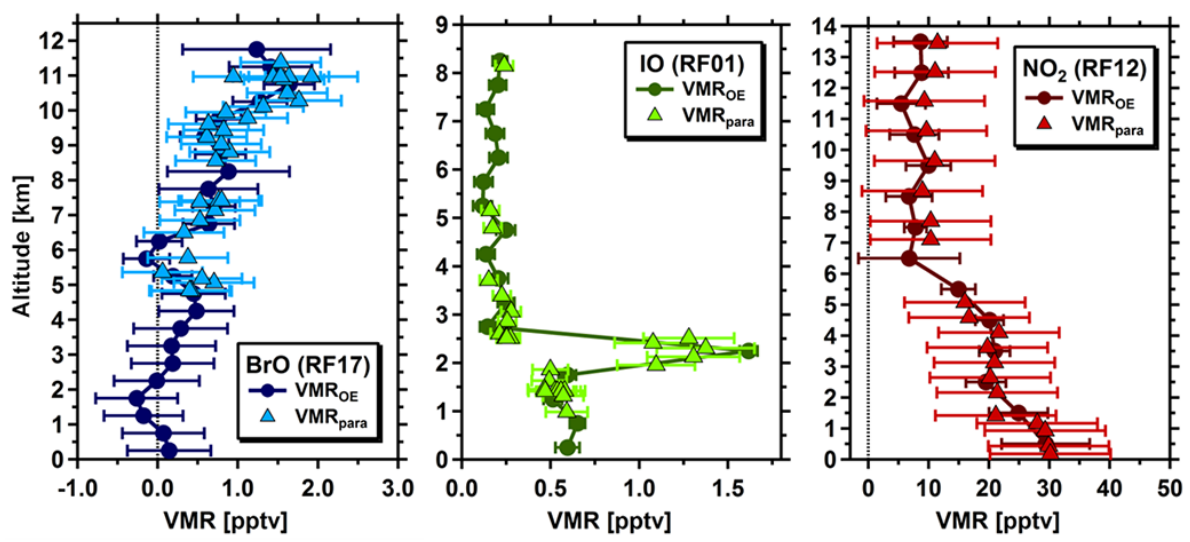

Figure 7. Comparison of VMR data retrieved from TORERO AMAX-DOAS data using the parameterization retrieval (para) or optimal estimation (OE) for select $\mathrm{BrO}$ (left), $\mathrm{IO}$ (middle) and $\mathrm{NO}_{2}$ (right) profiles.

the maximum aircraft altitude for which the $i=0$ parameterization retrieval provides profile information. The layer $n_{\max }$ is identical to the maximum aircraft altitude of each individual flight, unless high-altitude dSCD data have been filtered (clouds/quality assurance). Most TORERO flights targeted air masses that are rather homogenous with respect to trace gas distributions. In order to calculate $\mathrm{dSCD}_{\text {trop }}^{i}$ and $f_{\mathrm{TG}}^{i}$ (Eqs. 2 and 7), retrieved concentrations are averaged over the full flight, then interpolated and smoothed where needed, to minimize data scatter effects on the trace gas profile shape correction. During instances where the flight track crossed into stratospheric air, a second profile for $\mathrm{BrO}$ and $\mathrm{NO}_{2}$ is created and used to calculate $\mathrm{dSCD}_{\text {trop }}^{i}$ and $f_{\mathrm{TG}}^{i}$ for these time periods. IO VMR data often showed stronger variations below $5 \mathrm{~km}$ altitude within one flight. Here, up to three separate profiles per flight were created, while ensuring that profile-dependent differences above $5 \mathrm{~km}$ in the final $\mathrm{VMR}_{\text {para }}$ do not exceed error bounds. For the direct profile comparison discussed in the following section, the calculation of $\mathrm{dSCD}_{\text {trop }}^{i}$ and $f_{\mathrm{TG}}^{i}$ is based on results from the profile time period only. The errors reported for the parameterized data are those discussed above and in Sect. 4.3. In order to avoid a potential high bias created by filtering qualityassured dSCD data below the dSCD limit (see Sect. 3.2), respective $\mathrm{VMR}_{\text {para }}$ points are set to $0.2,0.02$ and $4 \mathrm{pptv}$ for $\mathrm{BrO}, \mathrm{IO}$ and $\mathrm{NO}_{2}$ respectively.

\subsection{Comparison of optimal estimation and parameterization profiles}

Figure 7 shows a comparison of VMR data retrieved by OE and by the parameterization method for select profiles of $\mathrm{BrO}$, IO and $\mathrm{NO}_{2}$ from the TORERO campaign for flights RF01, RF12 and RF17 (Volkamer et al., 2015; Wang et al., 2015). Parameterized VMRs are reported at aircraft altitude, i.e., the altitude for which the Box-AMFs are calculated. The spread seen within the same grid layer could be a reflection of a true trace gas gradient. Here the parameterization retrieval can provide additional information that is lost to the smoothing error of the OE method. The pronounced IO layer in the RF01 profile presents a good example of this effect. The $\mathrm{VMR}_{\text {para }}$ data points between 1.9 and $2.4 \mathrm{~km}$ clearly outline the IO peak at $2.25 \mathrm{~km}$, whereas the OE data report discrete values for $1.75,2.25$ and $2.75 \mathrm{~km}$. Note that the lines connecting the OE data points in Fig. 7 are only plotted to help guide the eye along the profile shape. All data points overlap within error bars, but the parameterization reveals steeper IO gradients indicative of less smoothing. In order to calculate correlations, the $\mathrm{VMR}_{\mathrm{OE}}$ data are interpolated to the $\mathrm{VMR}_{\text {para }}$ data. Results for all three trace gases are shown in Fig. 8. To increase statistics for the correlation, trace gas profiles from more flights are included, i.e., from RF01, RF04, RF05, RF12, RF14 and RF17 for all three trace gases (see also Wang et al., 2015, and Volkamer et al., 2015). Profile selection is based on availability of high-quality OE profiles. A least orthogonal distance fit is applied to consider the $x$ and $y$ errors. Offset and slopes are reported for a $95 \%$ confidence interval and included in the individual trace gas panels. Also here the agreement between $\mathrm{VMR}_{\mathrm{para}}$ and $\mathrm{VMR}_{\mathrm{OE}}$ is excellent. Offset values are insignificant, while slopes of $0.95 \pm 0.14$ for $\mathrm{BrO}, 1.00 \pm 0.12$ for $\mathrm{IO}$ and $0.87 \pm 0.15$ for $\mathrm{NO}_{2}$ are within expectations based on the sensitivity studies (see Sect. 4.3).

\subsection{TORERO BrO and IO VMR para $_{\text {results }}$}

Figure 9 shows $\mathrm{BrO}$ and $\mathrm{IO} \mathrm{VMR}_{\text {para }}$ results along flight tracks for all 17 TORERO RFs (but RF08). Altitudes of retrieved VMR data are plotted over latitude and are color coded by mixing ratios. $\mathrm{BrO}$ is consistently low in the boundary layer and almost never exceeds the detection limit of 0.5 pptv. Particularly in the tropical free troposphere, Fig. 9 shows a significant variability for BrO. VMRs larger $1 \mathrm{pptv}$ at altitudes above $8 \mathrm{~km}$ are also found in air without sig- 

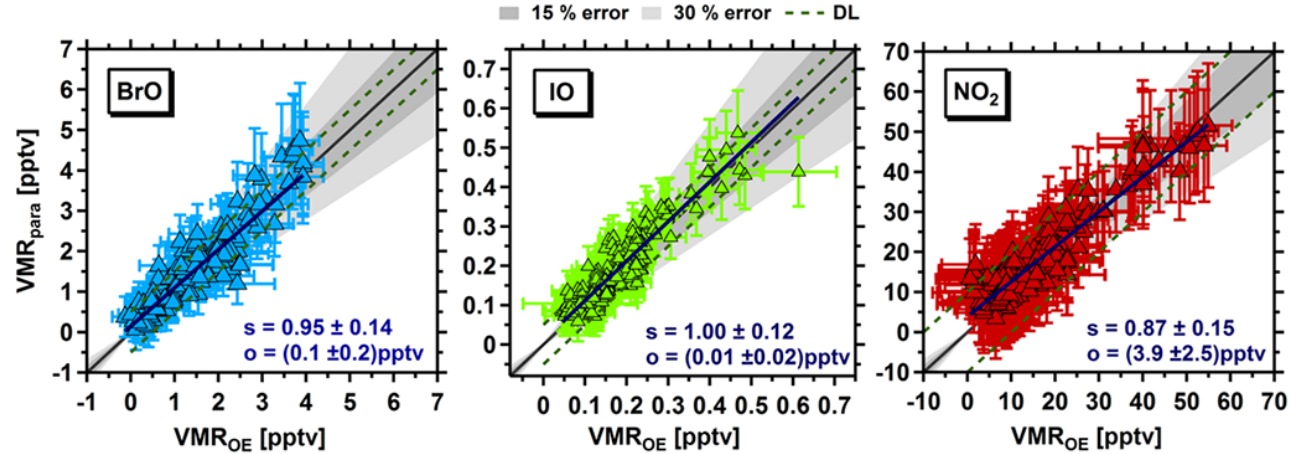

Figure 8. Correlations of TORERO AMAX-DOAS VMR data retrieved by parameterization (para) and optimal estimation (OE) for BrO (left), IO (middle) and $\mathrm{NO}_{2}$ (right). Grey shaded areas indicate 15 and $30 \%$ error; green dashed lines show trace gas detection limits. Linear fits and fit parameter (s: slope; o: offset) are included in each panel.
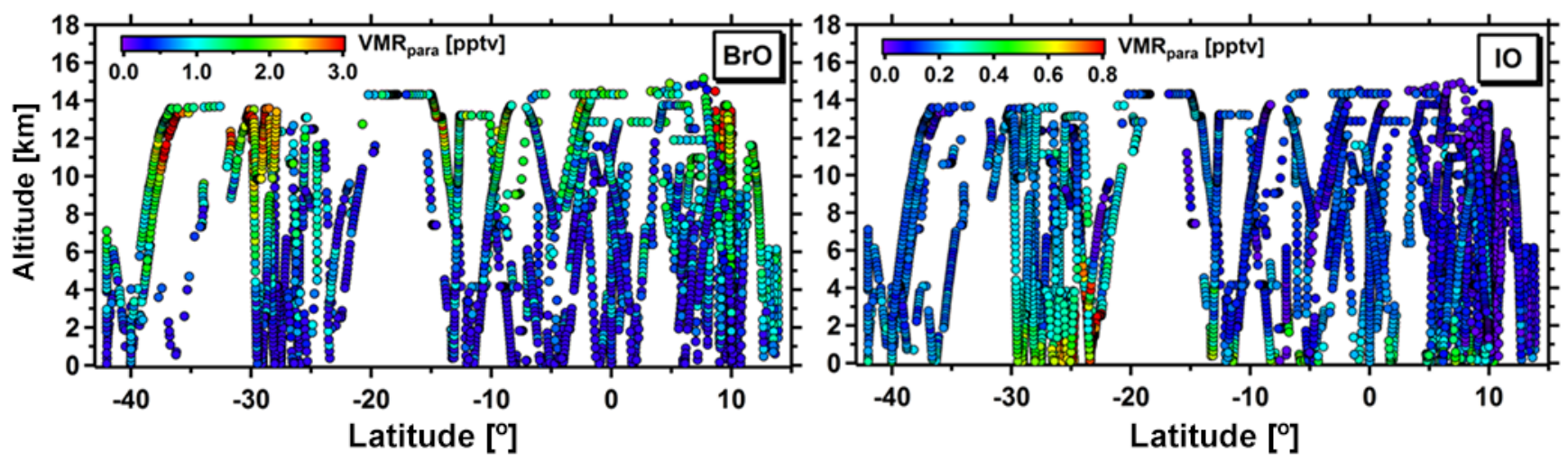

Figure 9. TORERO AMAX-DOAS BrO (left) and IO (right) VMR $\mathrm{VMara}_{\text {data }}$ for the complete campaign. Plotted are aircraft altitudes over latitude, color coded by $\mathrm{VMR}_{\text {para }}$. Longitudes covered are 70 to $105^{\circ} \mathrm{W}$.

nificant stratospheric influence and remain currently unexplained (Wang et al., 2015). In Fig. 10 TORERO BrO and IO VMR $\mathrm{Vara}_{\text {ra }}$ results are plotted as altitude-resolved whiskers, showing the mean with its $95 \%$ confidence interval $(\mathrm{CI})$ as uncertainty and 5, 25, 75 and 95 percentiles. The parameterization method provides better statistics. As expected, IO shows maxima in the boundary layer, but also a prevalent distribution throughout the troposphere. Our data suggest the existence of a hemispheric gradient with higher IO in the southern hemisphere. Large 95 percentiles between 1 and $4 \mathrm{~km}$ altitude are mainly driven by the IO layers observed near Antofagasta (see Fig. 7). These layers will be discussed elsewhere. For BrO, Wang et al. (2015) had noted atmospheric variability as a primary driver for error bars in the average profiles in pristine air. The mean $\mathrm{BrO}$ was $3.0 \mathrm{pptv}$ at $13.5 \mathrm{~km}$ and varied between $1.2 \mathrm{pptv}$ (RF04) and $4.0 \mathrm{pptv}$ (RF05). The overall data set also includes measurements in the outflow of terrestrial convection near the coast and has a lower mean $\mathrm{BrO} \mathrm{VMR}_{\text {para }}$ of $1.86 \pm 0.16 \mathrm{pptv}(95 \% \mathrm{CI}$, $N=162)$ at $13.5 \mathrm{~km}$ and $1.38 \pm 0.16 \mathrm{pptv}(95 \% \mathrm{CI}, N=78)$ at $14.5 \mathrm{~km}$. The decrease in $\mathrm{BrO}$ above $14 \mathrm{~km}$ altitude is significant and broadly consistent with findings by Werner et al. (2016). Decreasing BrO with increasing altitude had previously been observed during the RF04 case study (Wang et al., 2015). Notably, $\mathrm{VMR}_{\text {para }}$ and $\mathrm{VMR}_{\mathrm{OE}}$ are consistent to better $15 \%$ for all case study profiles discussed in our earlier work (see Fig. 8); these case studies had probed primarily air masses influenced by convection over oceans. The lower mean BrO in Fig. 10 compared to Fig. 2 of Wang et al. (2015) is hence primarily reflecting different air mass histories, consistent with the variability in $\mathrm{Br}_{y}$, and the hypothesis that seasalt-derived $\mathrm{Br}_{y}$ is a source for $\mathrm{BrO}$ in the upper free troposphere downwind of marine convection (Wang et al., 2015).

The observed halogen vertical distribution over the tropical Eastern Pacific appears to be complex and is not yet fully understood. Notably, recent measurements of low $\mathrm{BrO}$ in the tropical transition layer (TTL) over the tropical Eastern Pacific ocean during the ATTREX project (Werner et al., 2016) rely on knowledge about the tropospheric $\mathrm{BrO}$ profile below the aircraft for a priori information (Volkamer et al., 2015; Wang et al., 2015). If the TORERO observations are representative of the troposphere during ATTREX, the lower mean tropospheric $\mathrm{BrO}$ of $\mathrm{VMR}_{\text {para }}$ in Fig. 10 suggests that current TTL BrO estimates could be lower limits. 


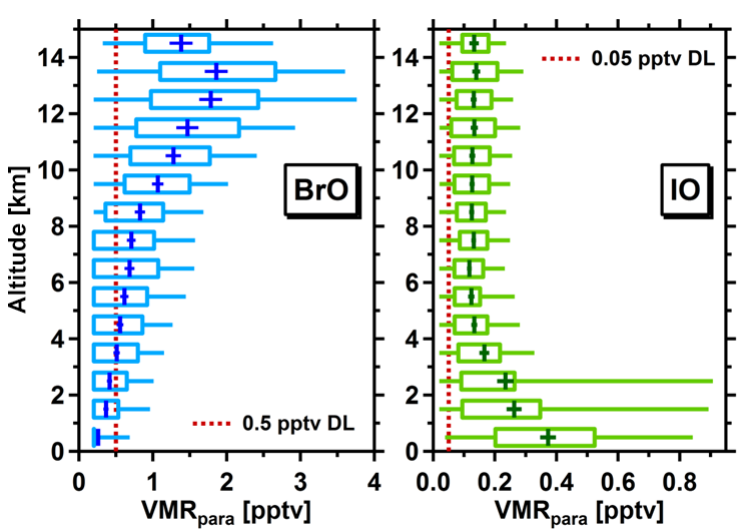

Figure 10. TORERO AMAX-DOAS BrO (left) and IO (right) $\mathrm{VMR}_{\text {para }}$ data for the complete campaign. Plotted are $1 \mathrm{~km}$ altitude means with their $95 \%$ confidence interval as uncertainty in darker colors, while the lighter colored whiskers denote 5, 25, 75 and 95 percentiles.

A BrO maximum at altitudes between 12 and $14 \mathrm{~km}$, with decreasing $\mathrm{BrO}$ at higher and lower altitudes, is currently not captured by global models (Schmidt et al., 2016; Sherwen et al., 2016a). Furthermore, aerosol bromide is frequently detected in particles in the upper troposphere and lower stratosphere (Murphy and Thomson, 2000), but the bromine mass concentration in these particles is currently not well known. The vertical distribution of $\mathrm{BrO}$ in the upper troposphere and lower stratosphere is affected by uncertainties and variability of $\mathrm{Br}_{y}$ sources to the free troposphere (very short lived species and sea-salt derived $\mathrm{Br}_{y}$ ), gas-phase $\mathrm{Br}_{y}$ partitioning, heterogeneous reactions on aerosol and ice surfaces, uncertain particulate bromide mass in the free troposphere and uncertainties about $\mathrm{Br}_{y}$ wet deposition. Simultaneous measurements of $\mathrm{BrO}$, other gas-phase $\mathrm{Br}_{y}$ species and particulate bromide are desirable.

The parameterization retrieval of VMRs along complete flight tracks enables a summary view of AMAX-DOAS results, which allows an assessment on the consistency of data variability or gradients across the whole study area. Based on the number of available EA $0^{\circ}$ spectra, a parameterization duty cycle is defined, which expresses the fraction of EA $0^{\circ} \mathrm{dSCD}$ measurements that are converted into VMRs. A total of $7124 \mathrm{BrO}$ dSCD measurements and $7168 \mathrm{IO}$ dSCD measurements were processed. Due to data quality, cloud and parameterization method filters, respectively, 24.3, 22.4 and $10.3 \%$ of the $\mathrm{BrO}$ data points and 10.6, 26.2 and $3.2 \%$ of the IO data points were filtered. The resulting duty cycle for the quality-assured VMR retrievals were $55.4 \%$ for $\mathrm{BrO}$ and $81.4 \%$ for IO before cloud filters and 44.3 and $60.1 \%$ for $\mathrm{BrO}$ and IO after cloud filters. Notably, the method filter removes the least number of data points for both trace gases, which underlines the statistical advantage of the parameterization method over OE. Based on these numbers, the devel- opment of an advanced cloud treatment has good potential to further improve the duty cycle.

\section{Conclusions and outlook}

The parameterization retrieval is a robust tool to convert AMAX-DOAS EA $0^{\circ}$ dSCDs of $\mathrm{BrO}, \mathrm{IO}$ and $\mathrm{NO}_{2}$ directly into VMRs along a flight track. Flight tracks that vary with altitude frequently provide the best results, because the iterative approach increases the accuracy of $\mathrm{VMR}_{\text {para }}$ by utilizing profile information gained from ascent or descent measurements. The magnitude of the stratospheric correction is constrained from measurements of EA $10^{\circ} \mathrm{dSCD}$ at high altitude. Based on our sensitivity studies on simulated data and application to field data, we conclude the following:

- The method is applicable over a wide range of atmospheric conditions and measurement geometries. VMRs of trace gases with significant stratospheric contributions to the VCDs can be retrieved for SZAs 0 to $60^{\circ}$ and for tropospheric trace gases for SZAs 0 to $70^{\circ}$, the latter being the full range covered by our sensitivity studies. $\mathrm{VMR}_{\text {para }}$ data are on average within $10-15 \%$ of $\mathrm{VMR}_{\text {true }}$. Errors that arise from suboptimal reference spectra are either accounted for by the $\mathrm{dSCD}_{\mathrm{c}}^{i}$ correction or are avoided by applying filters. Actively minimizing $\mathrm{SCD}_{\text {ref }}$ based on reference selection improves the accuracy of the parameterization retrieval.

- The comparison of $\mathrm{VMR}_{\text {para }}$ field data with $\mathrm{VMR}_{\mathrm{OE}}$ shows excellent agreement within the error bounds established by the sensitivity studies. Correlations of $13 \%$ and better are within expectations and further corroborate that the parameterization retrieval is suitable for the analysis of field data.

- Using $\mathrm{O}_{4} \mathrm{dSCDs}$ as scaling factors for aerosol extinction is a viable tool for altitude ranges between 0 and $15 \mathrm{~km}$ but not at higher altitudes, where $\mathrm{O}_{4}$ contributions from outside $S$ are a significant fraction of the measured $\mathrm{O}_{4}$ dSCDs and become difficult to account for.

- The retrieval is straightforward for gases that do not have a significant presence in the stratosphere. For gases with a significant presence in the stratosphere, the error can be reduced by following the recommendations given in Sect. 4.3.3.

- The TORERO VMR retrieval has a duty cycle of 55.4 and $81.4 \%$ for $\mathrm{BrO}$ and $\mathrm{IO}$ before cloud filtering and 44.3 and $60.1 \%$ after. Less than $11 \%$ of data points are removed by the method filters, which underlines the statistical advantage of the parameterization method over OE. 
- TORERO BrO and IO retrievals show halogen abundances over the tropical Eastern Pacific that are not completely understood, with implications for ozone depletion, atmospheric oxidation capacity and mercury oxidation (Wang et al., 2015; Schmidt et al., 2016; Sherwen et al., 2016a, b). Significant features like the $\mathrm{BrO}$ decrease above $14 \mathrm{~km}$ or the elevated IO layers near Antofagasta warrant further investigation. For future use, the method can easily be adapted for the retrieval of other absorbers like glyoxal, formaldehyde or HONO. The inherently fast conversion of dSCDs into VMRs can also serve as a tool for near-real-time VMR retrievals in the field. Future work will include optimizing the parameterization retrieval for (1) polluted environments, i.e., atmospheres with high $\mathrm{NO}_{2}$ and/or aerosol extinction; (2) SZA conditions outside current filters' and (3) minimizing the need for cloud filtering.

\section{Data availability}

The AMAX-DOAS BrO and IO data are available from the TORERO data archive: http://data.eol.ucar.edu/master_list/ ?project=TORERO. The TORERO data set is open for use by the public, subject to the following data policy: https: //www.eol.ucar.edu/node/4527. The archive contains aircraft and atmosphere state parameters, in situ measurements, flight videos and RAQMS and HSRL data. Specialized AMAXDOAS data products can be obtained from the authors upon request.

\section{The Supplement related to this article is available online at doi:10.5194/amt-9-5655-2016-supplement.}

Acknowledgements. The TORERO project was funded by the National Science Foundation under award AGS-1104104 (PI: R. Volkamer). The involvement of the NSF-sponsored Lower Atmospheric Observing Facilities, managed and operated by the National Center for Atmospheric Research (NCAR) Earth Observing Laboratory (EOL), is acknowledged. R. Volkamer acknowledges financial support from National Science Foundation Faculty Early Career Development (CAREER) award ATM-0847793, Department of Energy award DE-SC0006080 and Electric Power Research Institute (EPRI) contracts EPP27450/C13049 and EP-P32238/C14974 that supported the development of the AMAX-DOAS instrument and software/data analysis tools used in this study. We thank S. Baidar for support on data analysis, and Edwin W. Eloranta, Bruce Morley and Scott Spuler for HSRL data (UCAR/NCAR - Earth Observing Laboratory. 2016. GV high spectral resolution lidar (HSRL) data in netcdf format, version 1.0. doi:10.5065/D66H4FMX.

Edited by: M. Van Roozendael

Reviewed by: two anonymous referees

\section{References}

Baidar, S., Volkamer, R., Alvarez, R., Brewer, A., Davies, F., Langford, A., Oetjen, H., Pearson, G., Senff, C., and Hardesty, R. M.: Combining Active and Passive Airborne Remote Sensing to Quantify $\mathrm{NO}_{2}$ and $\mathrm{O}_{x}$ Production near Bakersfield, CA, Br. J. Environ. Clim. Chang., 3, 566-586, doi:10.9734/BJECC/2013/5740, 2013a.

Baidar, S., Oetjen, H., Coburn, S., Dix, B., Ortega, I., Sinreich, R., and Volkamer, R.: The CU Airborne MAX-DOAS instrument: vertical profiling of aerosol extinction and trace gases, Atmos. Meas. Tech., 6, 719-739, doi:10.5194/amt-6-719-2013, 2013b.

Baidar, S., Hardesty, R. M., Kim, S.-W., Langford, A. O., Oetjen, H., Senff, C., Trainer, M., and Volkamer, R.: Weakening of the Weekend Ozone Effect over California's South Coast Air Basin, Geophys. Res. Lett., 42, 9457-9464, doi:10.1002/2015GL066419, 2015.

Bruns, M., Buehler, S. A., Burrows, J. P., Richter, A., Rozanov, A., Wang, P., Heue, K. P., Platt, U., Pundt, I., and Wagner, T.: $\mathrm{NO}_{2}$ Profile retrieval using airborne multi axis UV-visible skylight absorption measurements over central Europe, Atmos. Chem. Phys., 6, 3049-3058, doi:10.5194/acp-6-3049-2006, 2006.

Coburn, S., Dix, B., Edgerton, E., Holmes, C. D., Kinnison, D., Liang, Q., ter Schure, A., Wang, S., and Volkamer, R.: Mercury oxidation from bromine chemistry in the free troposphere over the southeastern US, Atmos. Chem. Phys., 16, 3743-3760, doi:10.5194/acp-16-3743-2016, 2016.

Deutschmann, T., Beirle, S., Frieß, U., Grzegorski, M., Kern, C., Kritten, L., Platt, U., Prados-Román, C., Puíte, J., Wagner, T., Werner, B., and Pfeilsticker, K.: The Monte Carlo atmospheric radiative transfer model McArtim: Introduction and validation of Jacobians and 3D features, J. Quant. Spectrosc. Ra., 112, 11191137, doi:10.1016/j.jqsrt.2010.12.009, 2011.

Dix, B., Brenninkmeijer, C. A. M., Frieß, U., Wagner, T., and Platt, U.: Airborne multi-axis DOAS measurements of atmospheric trace gases on CARIBIC long-distance flights, Atmos. Meas. Tech., 2, 639-652, doi:10.5194/amt-2-639-2009, 2009.

Dix, B., Baidar, S., Bresch, J. F., Hall, S. R., Schmidt, K. S., Wang, S., and Volkamer, R.: Detection of iodine monoxide in the tropical free troposphere., P. Natl. Acad. Sci. USA, 110, 2035-2040, doi:10.1073/pnas.1212386110, 2013.

Dubovik, O., Holben, B., Eck, T., Smirnov, A., Kaufman, Y., King, M., Tanre, D., and Slutsker, I.: Variability of absorption and optical properties of key aerosol types observed in worldwide locations, J. Atmos. Sci., 59, 590-608, doi:10.1175/15200469(2002)059<0590:VOAAOP>2.0.CO;2, 2002.

Fayt, C. and Van Roozendael, M.: WinDOAS 2.1-Software user manual, 2001.

Henyey, L. C. and Greenstein, J. L.: Diffuse radiation in the Galaxy, Astrophys. J., 93, 70, doi:10.1086/144246, 1941.

Heue, K.-P., Richter, A., Bruns, M., Burrows, J. P., v. Friedeburg, C., Platt, U., Pundt, I., Wang, P., and Wagner, T.: Validation of SCIAMACHY tropospheric $\mathrm{NO}_{2}$-columns with AMAXDOAS measurements, Atmos. Chem. Phys., 5, 1039-1051, doi:10.5194/acp5-1039-2005, 2005.

Heue, K.-P., Brenninkmeijer, C. A. M., Baker, A. K., RautheSchöch, A., Walter, D., Wagner, T., Hörmann, C., Sihler, H., Dix, B., Frieß, U., Platt, U., Martinsson, B. G., van Velthoven, P. F. J., Zahn, A., and Ebinghaus, R.: $\mathrm{SO}_{2}$ and $\mathrm{BrO}$ observation in the plume of the Eyjafjallajökull volcano 2010: CARIBIC 
and GOME-2 retrievals, Atmos. Chem. Phys., 11, 2973-2989, doi:10.5194/acp-11-2973-2011, 2011.

Heue, K.-P., Riede, H., Walter, D., Brenninkmeijer, C. A. M., Wagner, T., Frieß, U., Platt, U., Zahn, A., Stratmann, G., and Ziereis, H.: CARIBIC DOAS observations of nitrous acid and formaldehyde in a large convective cloud, Atmos. Chem. Phys., 14, 66216642, doi:10.5194/acp-14-6621-2014, 2014.

Hönninger, G., von Friedeburg, C., and Platt, U.: Multi axis differential optical absorption spectroscopy (MAX-DOAS), Atmos. Chem. Phys., 4, 231-254, doi:10.5194/acp-4-231-2004, 2004.

Irie, H., Takashima, H., Kanaya, Y., Boersma, K. F., Gast, L., Wittrock, F., Brunner, D., Zhou, Y., and Van Roozendael, M.: Eightcomponent retrievals from ground-based MAX-DOAS observations, Atmos. Meas. Tech., 4, 1027-1044, doi:10.5194/amt-41027-2011, 2011.

Melamed, M. L., Solomon, S., Daniel, J. S., Langford, A. O., Portmann, R. W., Ryerson, T. B., Nicks, Jr., D. K., and McKeen, S. A.: Measuring reactive nitrogen emissions from point sources using visible spectroscopy from aircraft, J. Environ. Monit., 5, 2934, doi:10.1039/b204220g, 2003.

Merlaud, A., Van Roozendael, M., Theys, N., Fayt, C., Hermans, C., Quennehen, B., Schwarzenboeck, A., Ancellet, G., Pommier, M., Pelon, J., Burkhart, J., Stohl, A., and De Mazière, M.: Airborne DOAS measurements in Arctic: vertical distributions of aerosol extinction coefficient and $\mathrm{NO}_{2}$ concentration, Atmos. Chem. Phys., 11, 9219-9236, doi:10.5194/acp-11-9219-2011, 2011.

Murphy, D. M. and Thomson, D. S.: Halogen ions and NO+ in the mass spectra of aerosols in the upper troposphere and lower stratosphere, Geophys. Res. Lett., 27, 3217-3220, doi:10.1029/1999GL011267, 2000.

Oetjen, H., Baidar, S., Krotkov, N. A., Lamsal, L. N., Lechner, M., and Volkamer, R.: Airborne MAX-DOAS measurements over California: Testing the NASA OMI tropospheric $\mathrm{NO}_{2}$ product, J. Geophys. Res.-Atmos., 118, 7400-7413, doi:10.1002/jgrd.50550, 2013.

Perner, D. and Platt, U.: Detection of nitrous acid in the atmosphere by differential optical absorption, Geophys. Res. Lett., 6, 917920, doi:10.1029/GL006i012p00917, 1979.

Pierce, R. B., Al-Saadi, J. A., Schaack, T., Lenzen, A., Zapotocny, T., Johnson, D., Kittaka, C., Buker, M., Hitchman, M. H., Tripoli, G., Fairlie, T. D., Olson, J. R., Natarajan, M., Crawford, J., Fishman, J., Avery, M., Browell, E. V., Creilson, J., Kondo, Y., and Sandholm, S. T.: Regional Air Quality Modeling System (RAQMS) predictions of the tropospheric ozone budget over east Asia, J. Geophys. Res.-Atmos., 108, 8825, doi:10.1029/2002JD003176, 2003.

Pierce, R. B., Schaack, T., Al-Saadi, J. A., Fairlie, T. D., Kittaka, C., Lingenfelser, G., Natarajan, M., Olson, J., Soja, A., Zapotocny, T., Lenzen, A., Stobie, J., Johnson, D., Avery, M. A., Sachse, G. W., Thompson, A., Cohen, R., Dibb, J. E., Crawford, J., Rault, D., Martin, R., Szykman, J., and Fishman, J.: Chemical data assimilation estimates of continental U.S. ozone and nitrogen budgets during the Intercontinental Chemical Transport Experiment-North America, J. Geophys. Res., 112, D12S21, doi:10.1029/2006JD007722, 2007.

Platt, U.: Differential Optical Absorption Spectroscopy (DOAS), in Chemical Analysis Series 127: Air monitoring by spectroscopic techniques, edited by: Sigrist, M. W., 27-84, John Wiley \& Sons, Inc., New York, 1994.
Platt, U. and Stutz, J.: Differential Optical Absorption Spectroscopy, Springer, Heidelberg, ISBN-13: 978-3-540-75776-4, 2008.

Prados-Roman, C., Butz, A., Deutschmann, T., Dorf, M., Kritten, L., Minikin, A., Platt, U., Schlager, H., Sihler, H., Theys, N., Van Roozendael, M., Wagner, T., and Pfeilsticker, K.: Airborne DOAS limb measurements of tropospheric trace gas profiles: case studies on the profile retrieval of $\mathrm{O}_{4}$ and $\mathrm{BrO}$, Atmos. Meas. Tech., 4, 1241-1260, doi:10.5194/amt-4-1241-2011, 2011.

Schmidt, J. A., Jacob, D. J., Horowitz, H. M., Hu, L., Sherwen, T., Evans, M. J., Liang, Q., Suleiman, R. M., Oram, D. E., Le Breton, M., Percival, C. J., Wang, S., Dix, B., and Volkamer, R.: Modeling the observed tropospheric BrO background: Importance of multiphase chemistry and implications for ozone, $\mathrm{OH}$, and mercury, J. Geophys. Res.-Atmos., 121, 11819-11835, doi:10.1002/2015jd024229, 2016.

Schreier, S. F., Richter, A., Wittrock, F., and Burrows, J. P.: Estimates of free-tropospheric $\mathrm{NO}_{2}$ and $\mathrm{HCHO}$ mixing ratios derived from high-altitude mountain MAX-DOAS observations at midlatitudes and in the tropics, Atmos. Chem. Phys., 16, 28032817, doi:10.5194/acp-16-2803-2016, 2016.

Sherwen, T., Schmidt, J. A., Evans, M. J., Carpenter, L. J., Großmann, K., Eastham, S. D., Jacob, D. J., Dix, B., Koenig, T. K., Sinreich, R., Ortega, I., Volkamer, R., Saiz-Lopez, A., PradosRoman, C., Mahajan, A. S., and Ordóñez, C.: Global impacts of tropospheric halogens $(\mathrm{Cl}, \mathrm{Br}, \mathrm{I})$ on oxidants and composition in GEOS-Chem, Atmos. Chem. Phys., 16, 12239-12271, doi:10.5194/acp-16-12239-2016, 2016a.

Sherwen, T., Evans, M. J., Carpenter, L. J., Andrews, S. J., Lidster, R. T., Dix, B., Koenig, T. K., Sinreich, R., Ortega, I., Volkamer, R., Saiz-Lopez, A., Prados-Roman, C., Mahajan, A. S., and Ordóñez, C.: Iodine's impact on tropospheric oxidants: a global model study in GEOS-Chem, Atmos. Chem. Phys., 16, 11611186, doi:10.5194/acp-16-1161-2016, $2016 \mathrm{~b}$.

Sinreich, R., Coburn, S., Dix, B., and Volkamer, R.: Ship-based detection of glyoxal over the remote tropical Pacific Ocean, Atmos. Chem. Phys., 10, 11359-11371, doi:10.5194/acp-1011359-2010, 2010.

Sinreich, R., Merten, A., Molina, L., and Volkamer, R.: Parameterizing radiative transfer to convert MAX-DOAS dSCDs into near-surface box-averaged mixing ratios, Atmos. Meas. Tech., 6, 1521-1532, doi:10.5194/amt-6-1521-2013, 2013.

Spinei, E., Cede, A., Herman, J., Mount, G. H., Eloranta, E., Morley, B., Baidar, S., Dix, B., Ortega, I., Koenig, T., and Volkamer, R.: Ground-based direct-sun DOAS and airborne MAX-DOAS measurements of the collision-induced oxygen complex, $\mathrm{O}_{2} \mathrm{O}_{2}$, absorption with significant pressure and temperature differences, Atmos. Meas. Tech., 8, 793-809, doi:10.5194/amt-8-793-2015, 2015.

Thalman, R. and Volkamer, R.: Temperature dependent absorption cross-sections of $\mathrm{O}_{2}-\mathrm{O}_{2}$ collision pairs between 340 and $630 \mathrm{~nm}$ and at atmospherically relevant pressure, Phys. Chem. Chem. Phys., 15, 15371-15381, doi:10.1039/c3cp50968k, 2013.

Volkamer, R., Baidar, S., Campos, T. L., Coburn, S., DiGangi, J. P., Dix, B., Eloranta, E. W., Koenig, T. K., Morley, B., Ortega, I., Pierce, B. R., Reeves, M., Sinreich, R., Wang, S., Zondlo, M. A., and Romashkin, P. A.: Aircraft measurements of BrO, IO, glyoxal, $\mathrm{NO}_{2}, \mathrm{H}_{2} \mathrm{O}, \mathrm{O}_{2}-\mathrm{O}_{2}$ and aerosol extinction profiles in the tropics: comparison with aircraft-/ship-based in situ 
and lidar measurements, Atmos. Meas. Tech., 8, 2121-2148, doi:10.5194/amt-8-2121-2015, 2015.

Wagner, T., Dix, B., Friedeburg, C. v., Frieß, U., Sanghavi, S., Sinreich, R., and Platt, U.: MAX-DOAS $\mathrm{O}_{4}$ measurements: A new technique to derive information on atmospheric aerosolsPrinciples and information content, J. Geophys. Res.-Atmos., 109, D22205, doi:10.1029/2004JD004904, 2004.

Wagner, T., Deutschmann, T., and Platt, U.: Determination of aerosol properties from MAX-DOAS observations of the Ring effect, Atmos. Meas. Tech., 2, 495-512, doi:10.5194/amt-2-4952009, 2009.

Wang, P., Richter, A., Bruns, M., Rozanov, V. V., Burrows, J. P., Heue, K.-P., Wagner, T., Pundt, I., and Platt, U.: Measurements of tropospheric $\mathrm{NO}_{2}$ with an airborne multi-axis DOAS instrument, Atmos. Chem. Phys., 5, 337-343, doi:10.5194/acp-5-337-2005, 2005.

Wang, P., Richter, A., Bruns, M., Burrows, J. P., Scheele, R., Junkermann, W., Heue, K.-P., Wagner, T., Platt, U., and Pundt, I.: Airborne multi-axis DOAS measurements of tropospheric $\mathrm{SO}_{2}$ plumes in the Po-valley, Italy, Atmos. Chem. Phys., 6, 329-338, doi:10.5194/acp-6-329-2006, 2006.
Wang, S., Schmidt, J. A., Baidar, S., Coburn, S., Dix, B., Koenig, T. K., Apel, E., Bowdalo, D., Campos, T. L., Eloranta, E., Evans, M. J., DiGangi, J. P., Zondlo, M. A., Gao, R.-S., Haggerty, J. A., Hall, S. R., Hornbrook, R. S., Jacob, D., Morley, B., Pierce, B., Reeves, M., Romashkin, P., Ter Schure, A., and Volkamer, R.: Active and widespread halogen chemistry in the tropical and subtropical free troposphere., P. Natl. Acad. Sci. USA, 112, 92819286, doi:10.1073/pnas.1505142112, 2015.

Werner, B., Stutz, J., Spolaor, M., Scalone, L., Raecke, R., Festa, J., Colosimo, F., Cheung, R., Tsai, C., Hossaini, R., Chipperfield, M. P., Taverna, G. S., Feng, W., Elkins, J. W., Fahey, D. W., Gao, R.-S., Hintsa, E. J., Thornberry, T. D., Moore, F. L., Navarro, M. A., Atlas, E., Daube, B., Pittman, J., Wofsy, S., and Pfeilsticker, K.: Probing the subtropical lowermost stratosphere, tropical upper troposphere, and tropopause layer for inorganic bromine, Atmos. Chem. Phys. Discuss., doi:10.5194/acp-2016656, in review, 2016. 